\title{
EFEITOS DA EDUCAÇÃO DOS PAIS SOBRE O RENDIMENTO ESCOLAR DOS FILHOS VIA MEDIAÇÃO DAS CONDIÇÕES SOCIOECONÔMICAS
}

\author{
Mateus Mota dos Santos* \\ Francisca Zilania Mariano ${ }^{\dagger}$ \\ EDWARd Martins Costa ${ }^{\ddagger}$
}

\begin{abstract}
Resumo
Este trabalho busca avaliar os efeitos da educação dos pais sobre o rendimento escolar de alunos. O método contrafactual de mediação desenvolvido por Imai et al. (2010) foi aplicado às informações extraídas do SAEB, Censo Escolar e Indicadores Sociais, disponibilizadas pelo INEP (2015). Os resultados evidenciam que o efeito de mediação causal ganha força à medida que o nível de educação dos pais aumenta, indicando que parte do efeito da escolaridade dos pais é potencializado pelo nível socioeconômico familiar. Além disso, a influência indireta da escolaridade dos pais via mediação das condições socioeconômicas é maior para filhos do sexo masculino.
\end{abstract}

Palavras-chave: efeito de mediação causal, educação dos pais, rendimento escolar

\begin{abstract}
This study aims to analyze the effects of parents' education on the school performance of the students. The Causal Mediation Effect method was applied to the information extracted from SAEB, School Census, and the Platform of Social Indicators made available by INEP (2015). The results showed that the causal mediation effect gains strength as parents 'level of education increases, indicating that part of the effect of parents' schooling is strengthened by the family socioeconomic level. The indirect influence of parents' schooling through mediation of socioeconomic conditions, on average, is higher for the male children.
\end{abstract}

Keywords: effect causal mediation, parents' education, school performance JEL classification: A21, C21, I21

DOI: http://dx.doi .org/10.11606/1980-5330/ea144751

\footnotetext{
* Mestrando em Economia CAEN/UFC. E-mail: matheus12_mota@hotmail.com

† Doutora em Economia e Professora UFC/Sobral. E-mail: zilania@ufc.br

‡ Doutor em Economia e Professor PPGER/UFC. E-mail: edwardcosta@ufc.br
} 


\section{Introdução}

A educação tem sido um tema de ampla discussão na literatura acadêmica devido à sua influência sobre os retornos privados, medidos pela acumulação de capital humano e, consequentemente, sobre o crescimento e desenvolvimento de uma dada região ou país, já que, maiores níveis de escolaridade estão associados à maior produtividade dos fatores de produção. Além disso, estudos evidenciam a educação como uma das principais fontes sociais de externalidades positivas, capaz de reduzir os níveis de desigualdades de renda (Becker \& Chiswick 1966, Souza et al. 2013), além da redução significativa da criminalidade (Lochner \& Moretti 2004). Ressalta-se também que, as influências do capital humano tornam-se ainda mais eficientes e significativas para a explicação do crescimento econômico quando se utiliza como proxy para a mesma, a qualidade da educação em vez da quantidade. Hanushek \& Woessmann (2010) evidenciam que a inclusão de uma variável indicadora da qualidade educacional dos indivíduos eleva o poder de explicação do crescimento econômico, de modo que o coeficiente de determinação do modelo eleva-se de $25 \%$ para $73 \%$, após a inclusão da qualidade da educação.

Há uma diversidade de fatores que podem estar associados às melhorias na qualidade da educação. Soares (2004) argumenta que estes podem ser agregados em três grupos específicos: características individuais dos alunos, família e escola. Estudos relacionados ao desempenho escolar encontraram uma influência positiva dos insumos escolares sobre o progresso na qualidade da educação (Albernaz et al. 2002, Nieto \& Ramos 2013). Entretanto, evidências empíricas constatam que a qualidade da escola possui menor contribuição sobre os resultados acadêmicos dos alunos quando comparada ao background familiar dos mesmos (Coleman 1966, Felício \& Fernandes 2005, Araújo \& Almeida 2013, Palermo et al. 2014). Ademais, a influência de tais fatores difere entre gêneros (Peraita \& Sánchez 1998, Glick \& Sahn 2000, Chen 2009, Jerrim \& Micklewright 2011) e regiões (Barros \& Lam 1993, Melo \& Arakawa 2012, Medeiros \& de Oliveira 2013).

Os diferenciais na qualidade da educação estão associados não somente às diferenças na distribuição de insumos escolares, mas, também, nas disparidades do contexto socioeconômico dos alunos, as quais são geradas pelas diferenças no nível de escolaridade dos pais, já que, pais mais escolarizados estão mais propensos a adquirir maiores níveis de renda.

A literatura referente ao background familiar e desempenho escolar revela que há diferenças inter-regionais e entre gêneros, no que diz respeito às influências da escolaridade e nível socioeconômico dos pais sobre os resultados escolares dos filhos. Segundo de Serf'02 (2002), a renda dos pais é um importante determinante do investimento a ser destinado à educação dos filhos. Além disso, Vieira \& Tenório (2014) destacam que o efeito da educação dos pais sobre os resultados escolares dos filhos está fortemente relacionado às condições socioeconômicas da família, já que, a escolaridade de um indivíduo está intimamente associada ao nível socioeconômico de sua família.

Entretanto, tais estudos limitam-se apenas em estimar o grau de associação entre background familiar e habilidades dos alunos, sem conclusões a respeito das direções causais de tais variáveis. Com isso, a contribuição deste trabalho reside em considerar que, o efeito causal do nível de educação dos pais não se dá somente de forma direta, mas, também, de forma indireta via condição socioeconômica, a qual poderá potencializar tal efeito, pois, espera-se que ní- 
veis de escolaridade mais elevados estejam associados a melhores níveis de renda e, consequentemente, maior será o desempenho escolar dos filhos. Convém ressaltar que, estudos que não levam em consideração esse efeito indireto possivelmente vão superestimar os reais efeitos da educação dos pais, pois, a influência da educação dos pais pode ser potencializada pelo nível socioeconômico da família, principalmente nos níveis mais elevados de educação dos pais, já que estes terão maiores disponibilidades financeiras para investir na educação de seus filhos aumentando-se, assim, as chances de sucesso escolar destes.

Diante do exposto, este estudo tem por objetivo avaliar o efeito da educação dos pais via mediação das condições socioeconômicas sobre o rendimento escolar de alunos do $5^{\circ}$ ano do ensino fundamental da rede pública de ensino, levando-se em consideração a heterogeneidade de tais efeitos entre gênero e regiões, da área urbana do Brasil. Para tanto, este estudo utilizou as informações retiradas do SAEB, Censo Escolar e da Plataforma de Indicadores Sociais disponibilizadas pelo Instituto Nacional de Estudos e Pesquisas Educacionais Anísio Teixeira (2015b).

Visando atingir o objetivo proposto, aplicou-se o método de efeito de mediação causal desenvolvido por Imai et al. (2010), o qual permite capturar a parcela do efeito da educação dos pais sobre o desempenho escolar dos filhos que pode ser explicado por seu efeito no nível socioeconômico da família (variável mediadora), permitindo, assim, particionar o efeito médio total da escolaridade dos pais nos efeitos, direto e indireto (mediação), sendo que, neste último, o nível de instrução do pai e da mãe afeta indiretamente o desempenho escolar dos filhos via mediação do nível socioeconômico da família, o qual se encontra na via de causalidade entre a educação dos pais e o sucesso acadêmico dos filhos, até então, não levado em consideração pela literatura.

Diferentemente dos métodos de estimativas causais usuais ${ }^{1}$, a análise de mediação capta o efeito do caminho percorrido da variável de tratamento até afetar a variável de resultado potencial, por meio de uma variável intermediária que se encontra na via causal entre o tratamento e a variável de interesse. Nesse sentido, a mesma permite particionar o efeito médio total do tratamento em dois efeitos, direto e indireto, o qual não pode ser verificado nas demais abordagens, tais como, no método de variável instrumental, por exemplo, o qual assume que o tratamento afeta o resultado apenas indiretamente, eliminando-se, assim, a possibilidade de estimativa de outras vias causais. Outra vantagem desse estimador, segundo Imai et al. (2010), reside na correção da ignorabilidade do mediador por meio da identificação não paramétrica sob a ignorabilidade sequencial, o qual mensura resultados empíricos mais robustos.

Em sequência, o artigo está dividido nas seções: breve revisão de literatura referente aos determinantes do desempenho escolar e influências da escolaridade dos pais sobre o rendimento acadêmico dos filhos; fontes dos dados utilizadas e abordagem metodológica; resultados e considerações finais.

\footnotetext{
${ }^{1}$ Propensity Score Matching (PSM); Entropia; Diferença em Diferença; Variáveis Instrumentais (VI), dentre outros.
} 


\section{Referencial Teórico}

\subsection{Determinantes do Rendimento Escolar}

Na literatura acadêmica sobre desempenho escolar são utilizadas diferentes medidas para mensurar a qualidade da educação: frequência escolar, taxa de distorção idade-série, abandono escolar, além de proficiências em testes cognitivos e não cognitivos. Além do mais, muitos são os estudos, tanto a nível nacional quanto internacional, que investigam os principais fatores associados a tal desempenho, que de acordo com Soares (2004) podem ser agrupados em três grupos: características individuais dos alunos, família e escola.

Visando estimar o efeito dos recursos escolares sobre o desempenho acadêmico na Inglaterra, Levacic et al. (2005), a partir de dados do National Pupil Database (NPD) e Pupil Level Annual Schools Census (PLASC), encontram, por meio do método de Mínimos Quadrados Ordinários (MQO) e de Variáveis Instrumentais (VI), que elevações nas despesas por aluno além da redução da proporção de alunos por professor possui efeitos positivos e estatisticamente significativos sobre os resultados em Matemática e Ciências, realizadas por alunos com idade entre 14 e 15 anos, no ano de 2003. Além disso, os autores evidenciaram que, tais efeitos quando estimados por VI são, aproximadamente, até dez vezes maiores que os encontrados por MQO, mostrando que, a relação entre tais recursos e o desempenho dos alunos pode ser subestimada quando a endogeneidade entre os mesmos não é levada em consideração, já que, na Inglaterra, como destacam os autores, maiores recursos escolares são destinados as escolas com uma maior proporção de alunos com nível socioeconômico desfavorável. Ressalta-se também que esses recursos escolares possuem maiores efeitos sobre alunos de famílias mais pobres.

Fazendo uso da mesma fonte de dados, Steele et al. (2007) encontraram resultados similares. Por meio da análise de equações simultâneas multinível, estes encontram uma relação positiva e significativa entre os recursos escolares e o desempenho nas disciplinas de Matemática e Ciências. Ademais, os mesmos estimam que, um aumento de $£ 1000$ com despesas por aluno elevaria o desempenho escolar em 0,07 e 0,2 pontos, aproximadamente, em Matemática e Ciências, respectivamente, e que uma redução na proporção de alunos por professor levaria a um ganho no rendimento acadêmico de 0,12 e 0,13 pontos para as mesmas disciplinas, respectivamente.

No Brasil, Barbosa \& Fernandes (2001) analisaram os fatores associados a escola que influenciam os resultados em Matemática para alunos da $4^{\text {a }}$ série do ensino fundamental na Região Sudeste do Brasil. Com base na análise de um modelo multinível com três níveis (aluno, turma, escola) os autores ao realizar o controle por nível socioeconomico dos alunos, verificaram que a infraestrutura e equipamentos escolares explicam cerca de $54 \%$ da variabilidade do desempenho entre escolas. Ressalta-se também que ao controlar a infraestrutura e equipamentos escolares, os resultados evidenciam um alto poder explicativo das variáveis relacionadas aos professores e a interação destes com a turma para um bom desempenho acadêmico.

Ao estimar uma função de produção educacional para alunos da $8^{\text {a }}$ série, no Brasil, Albernaz et al. (2002), com base em informações do Sistema Nacional de Avaliação da Educação Básica (Saeb) de 1999 e, por meio da análise de modelos hierárquicos lineares verificaram que, aproximadamente, $80 \%$ da variância de rendimento entre escolas dizem respeito a diferenças socioeconô- 
micas dos alunos. Ademais, também é ressaltada a influência da escolaridade dos professores e da infraestrutura da escola para uma boa performance escolar.

Ao investigar os possíveis fatores que podem influenciar os resultados em Matemática de alunos do ensino fundamental e médio, Menezes Filho (2012), com base em microdados do SAEB de 2003 verificou que, além das características individuais dos alunos, as variáveis mais relevantes para explicar os resultados escolares dizem respeito às características da família, com destaque à educação da mãe, a quantidade de livros e trabalhar fora de casa, sendo que, esta última afeta negativamente o desempenho em Matemática. Os resultados também apontam para diferenças de gêneros, em que os homens, em média, possuem melhores resultados em Matemática quando comparados às mulheres, em todos os níveis de ensino. Ressalta-se também que, o autor encontra evidências de influência negativa do atraso escolar sobre o rendimento dos alunos, indicando que, alunos que já repetiram o ano, em média, possuem baixo desempenho se comparado àqueles que se encontram na série certa. Utilizando-se da mesma fonte de dados, para o ano de 2001, resultados similares são encontrados por Andrade e Laros (2007). Utilizando-se de um modelo multinível, o autor constatou que além do atraso escolar, alunos que trabalham fora do domicílio possuem menor desempenho quando comparados àqueles em situação diferente.

Soares \& Sátyro (2008) avaliaram as influências da infraestrutura da escola sobre o desempenho escolar no Brasil, medido pela taxa de distorção idadesérie para o ensino fundamental, com o auxílio de informações provenientes do Censo Escolar de 1998 a 2005 e, também, do Censo Demográfico de 2000. Os resultados apontam para a importância da infraestrutura da escola para um melhor resultado escolar, cujos efeitos são maiores para escolas que se encontram em piores situações.

Ao analisar os fatores associados à evasão escolar de alunos do ensino fundamental em Pernambuco, Sergipe, Pará, Rondônia, Mato Grosso do Sul e Goiás, Gonçalves et al. (2008), com o auxílio de modelos hierárquicos logísticos longitudinais encontraram uma associação negativa entre background familiar e evasão escolar, indicando que menores níveis socioeconômicos estão associados a maior probabilidade de desistência escolar do aluno. Além disso, os autores ressaltam a significância estatística de variáveis relacionadas à trajetória escolar passada do aluno, como repetência escolar anterior à $4^{\mathrm{a}}$ série. Os resultados também evidenciam que a probabilidade de evasão escolar média é maior na Região Nordeste do que nas demais regiões.

Fazendo uso de informações provenientes da Prova Brasil e Censo Escolar de 2005 de Araújo \& de Siqueira (2010), por meio de um modelo probit ordenado destacam a importância do contexto familiar, de alunos da $4^{\text {a }}$ série do ensino fundamental, sobre o desempenho escolar. Os resultados encontrados também apontam para diferenças de gênero, raça e região, de modo que, meninas e alunos negros registram desempenho inferior em Matemática, em comparação aos seus pares. Outra evidência importante é que alunos pertencentes à Região Nordeste estão mais propensos a obter menores notas em tal disciplina.

Utilizando-se de microdados do Programme of International Student Assessment (PISA) de 2006 e 2009, Nieto \& Ramos (2013) analisaram as influências da qualidade da escola e de seus professores sobre o desempenho escolar dos alunos. Por meio da decomposição de Oaxaca-Blinder os autores encon- 
traram evidências de que a qualidade da escola e dos professores possui maior poder explicativo do que as características individuais dos alunos. Diferentemente destes, Araújo \& Almeida (2013), ao analisar o desempenho de estudantes do $5^{\circ}$ ano do ensino fundamental do município de João Pessoa - PB, com base em microdados da Prova Brasil de 2001 e de informações do Censo Demográfico de 2010, averiguaram que além das características socioeconômicas da família, o perfil do aluno e a localização da escola, são as variáveis que mais influenciam os resultados dos alunos quando comparadas aos insumos escolares.

Por meio da análise longitudinal (2009 a 2011) e modelos logísticos multinível, Shirasu \& Arraes (2015) investigaram os fatores possivelmente associados à evasão e repetência escolar em escolas públicas do estado do Ceará, para o ensino médio. Dentre as estimativas obtidas, constatou-se que os fatores que mais contribuem para o abandono e repetência escolar dizem respeito ao desinteresse dos alunos pelos estudos e a repetência escolar em anos anteriores. Ressalta-se também que o nível de educação dos pais também se mostrou significativo para explicar a evasão e repetência dos alunos.

\subsection{Background Familiar e Desempenho Acadêmico}

Estudos empíricos a respeito do desempenho escolar evidenciam uma influência positiva e significativa do background familiar sobre o rendimento acadêmico dos alunos (Marbuah 2016, Palermo et al. 2014, Vieira \& Tenório 2014, de Serf'02 2002), e que os fatores associados ao background familiar exercem maior participação nos resultados escolares do que as características da própria escola (Coleman 1966, Felício \& Fernandes 2005, Araújo \& Almeida 2013, Palermo et al. 2014). Estudos apontam para a existência de uma heterogeneidade de tal relação entre regiões (Barros \& Lam 1993, Melo \& Arakawa 2012, Medeiros \& de Oliveira 2013) e, também, entre gêneros (Peraita \& Sánchez 1998, Glick \& Sahn 2000, Chen 2009, Jerrim \& Micklewright 2011).

Utilizando dados do Gansu Survery of Children and Families (GSCF) de 2000, para a área rural da China, Chen (2009) investiga a relação existente entre background familiar e o desempenho na educação básica em Matemática, levando em consideração características individuais das crianças, da família e escola. Por meio do método de variável instrumental (VI), o autor verificou que maiores níveis de escolaridade dos pais estão associados a melhores desempenhos dos filhos. Ao fazer uma distinção dos efeitos entre gêneros, os resultados evidenciam que a educação da mãe se mostra significativa apenas para meninas, enquanto que a escolaridade do pai influencia os resultados de ambos os filhos. Além do mais, o nível de instrução do pai possui maior associação com os resultados dos filhos que se encontram no extremo inferior da distribuição de notas, enquanto que para a mãe verifica-se o contrário.

Resultados semelhantes são encontrados por Glick \& Sahn (2000). Por meio de informações extraídas de uma pesquisa realizada em Conakry, principal centro urbano da Guiné, na África, em 1990, e com o auxílio de um modelo probit ordenado, os autores encontraram influências positivas e estatisticamente significativas dos níveis de educação e renda dos pais sobre os anos de escolaridade dos filhos. Além disso, tais efeitos diferem entre gêneros, sendo que, a educação do pai possui influências positivas sobre os anos de estudo de ambos os filhos, enquanto que o nível de instrução da mãe afeta apenas os anos de escolaridade das filhas. Em relação à renda familiar, esta tem 
efeito positivo e significativo apenas para as meninas, sem nenhuma influência para meninos. Com base em um modelo logit ordenado e, em microdados extraídos da pesquisa ECVT, na Espanha, Peraita \& Sánchez (1998) também encontraram uma associação positiva entre a renda familiar e os anos de escolaridade, e que tais influências diferem entre gêneros, sendo maiores para as meninas.

Jerrim \& Micklewright (2011) por meio de informações extraídas do Programmefor International Student Assessment (PISA) para o ano de 2003, levando em consideração todos os países da OCDE, com exceção do México e Japão, com base no método de regressão múltipla, também encontraram que quanto mais elevado for o nível de escolaridade dos pais melhores serão as habilidades dos filhos na disciplina de Matemática, e que tais efeitos diferem entre gênero. A educação da mãe possui maior influência sobre o rendimento escolar das filhas enquanto que a educação do pai possui maior participação nos resultados dos filhos.

Baseado em informações extraídas do Ghana Living Standards Survey 2012/2013, Marbuah (2016), por meio de análise de correlação de Parson e de regressão múltipla, encontra que maiores níveis de renda e escolaridade de pais estão associados a maiores níveis de educação dos filhos. Além disso, os resultados indicam que a educação do pai possui maior influência sobre a educação dos filhos em detrimento à escolaridade da mãe, no sistema básico de ensino.

de Serf'02 (2002), a partir de dados da National Longitudinal Survey of Youth (NLSY) de 1979 e 1998, também encontra uma relação positiva e significativa entre o background familiar, composta pelo nível de renda, escolaridade da mãe e tamanho da família, e a educação dos filhos, medida pelos anos de escolaridade, sendo que, tal influência é maior sobre indivíduos brancos, quando comparados a negros e hispânicos.

A relevância da qualidade da escola é evidenciada por Felício \& Fernandes (2005), os quais, por meio de um Índice de Theil e da decomposição de notas entre escola e background familiar encontraram evidências, para o estado de São Paulo, de que a escola explica entre 0 e $28,4 \%$ e, as características familiares, entre 8,7 e $34,44 \%$ dos diferenciais de rendimentos nas disciplinas de Português e Matemática, respectivamente, para alunos da $4^{\text {a }}$ série do ensino fundamental, indicando que o background familiar possui maior participação na explicação das desigualdades de notas dos alunos do que a própria escola. Resultados similares são encontrados no Relatório de Coleman (1966), o qual evidencia uma maior participação das características familiares em detrimento dos fatores escolares, como infraestrutura, no desempenho escolar. Além do mais, o mesmo também verificou que maiores níveis educacionais dos pais estão associados a melhores resultados escolares de seus filhos.

Barros \& Lam (1993), fazendo uso de dados da PNAD (1982) investigaram as diferenças de escolaridade entre as áreas urbanas da Região Nordeste e São Paulo, além de seus determinantes, com o auxílio de três modelos econométricos estimados por Mínimos Quadrados Ordinários (MQO), com exceção do terceiro, o qual se aplicou o método de variável instrumental (VI). No primeiro modelo, o desvio da regressão é tido como aleatório e independente dos níveis de escolaridade dos pais e renda familiar. No segundo, o desvio domiciliar depende do nível de instrução dos avós, fazendo com que a função resposta dependa não apenas da renda e escolaridade dos pais, mas também, da escolaridade dos avós. Por fim, no terceiro modelo utilizado pelos autores, a escolaridade dos avós é utilizada como instrumento para a educação dos pais 
dos alunos. De acordo com os resultados encontrados, a educação e renda dos pais possuem influências positivas sobre os anos de escolaridades dos filhos. Ademais, os achados apontam para existência de diferenças nas médias de escolaridade entre a Região Nordeste e São Paulo, com vantagem de 1,5 anos para esta última.

Melo \& Arakawa (2012) analisaram as diferenças regionais das influências do background familiar sobre o desempenho escolar no ENEM de 2008, restringindo a análise apenas para indivíduos que estavam concluindo o ensino médio, com idade entre 15 a 20 anos. Utilizando-se do método de MQO os autores encontraram uma relação positiva entre a educação e renda dos pais sobre os resultados potenciais dos filhos, em todas as regiões do Brasil. Ademais, por meio do teste estatístico de Chow, estes constaram que tal relação, entre o background familiar e desempenho no ENEM, possui diferenças estatisticamente significantes entre as regiões do país. Ressalta-se também que, os resultados encontrados pelos autores evidenciam que essa relação é mais forte em regiões menos desenvolvidas, enquanto que, para regiões mais desenvolvidas, o contrário é verificado.

As possíveis influências do background familiar sobre os resultados acadêmicos de alunos, nas grandes regiões do Brasil, também foram investigadas por Mendes \& Karruz (2012). Com base em microdados do ENEM de 2012 e análise de regressão múltipla, estimada por MQO, os autores constataram que o background familiar possui relação direta e significativa com o desempenho no ENEM. Os resultados também apontam para diferenças inter-regionais das influências da educação e renda dos pais sobre o desempenho escolar. As regiões Centro-Oeste e Sul registraram, respectivamente, maior influência da educação da mãe e do pai. Ressalta-se também que os resultados evidenciam que, em média, a educação do pai possui maior participação nos resultados do que o nível de instrução da mãe, em todos os estratos de escolaridade. No que diz respeito à renda familiar, esta possui maior e menor influência para o Nordeste e Sul, respectivamente.

Com base em informações extraídas da Pesquisa Nacional por Amostra de Domicílios (PNAD) para o ano de 2011, Medeiros \& de Oliveira (2013) apontam para diferenças educacionais entre as diferentes regiões do país, as quais são causadas não somente pelas diferenças entre as distribuições de características individuais e familiares, mas também, o modo pelo qual as diferentes regiões reagem a essas características. Os autores também constataram que, o estado de São Paulo possui os maiores níveis de escolaridade e que as regiões Norte e Nordeste possuem média de escolaridade mais baixa, com desvantagem média de 1,3 ano, quando comparadas ao estado de São Paulo.

A importância do background familiar também foi comprovada por Palermo et al. (2014) os quais estudaram as influências de diferentes fatores sobre o desempenho escolar em Matemática de alunos da rede pública de ensino. Para tanto, os autores utilizaram-se de informações retiradas da Prova Brasil e Censo Escolar de 2007, além do Censo Demográfico de 2000. Com o auxílio de Modelos de Regressão Hierárquica com três níveis (alunos, turmas e escolas) constataram que os fatores de maior participação no desempenho escolar são provenientes do background familiar.

Buscando avaliar a relação entre os níveis socioeconômicos e educação dos pais sobre o desempenho escolar dos filhos nos anos iniciais da educação básica no estado da Bahia, Vieira \& Tenório (2014), a partir da utilização de dados longitudinais do Projeto GERES 2005 e por meio de modelos hierárqui- 
cos lineares, constataram que os aspectos individuais dos alunos não afetam os resultados escolares iniciais, mas sim, o background familiar destes. As estimativas também revelam que a escolaridade dos pais está fortemente ligada ao nível socioeconômico da família. Logo, quanto maior o nível de instrução dos pais, maiores serão os níveis de renda da família e, consequentemente, melhores serão os resultados acadêmicos dos filhos.

A literatura referente ao background familiar e desempenho escolar revela que há diferenças inter-regionais e entre gêneros, no que diz respeito às influências da escolaridade e nível socioeconômico dos pais sobre os resultados escolares dos filhos. Entretanto, tais estudos limitam-se apenas em estimar o grau de associação entre background familiar e habilidades dos alunos, sem conclusões a respeito das direções causais de tais variáveis. Este estudo busca realizar uma avaliação dos efeitos causais da escolaridade dos pais sobre os resultados escolares dos filhos.

Segundo de Serf'02 (2002), a renda dos pais é um importante determinante da quantidade de dinheiro a ser destinado à educação dos filhos. Além disso, Vieira \& Tenório (2014) destacam que o efeito da educação dos pais sobre os resultados escolares dos filhos está fortemente relacionado às condições socioeconômicas da família, já que, a escolaridade de um indivíduo está intimamente associada ao nível socioeconômico de sua família. Considera-se neste estudo que o efeito causal do nível de educação dos pais não se dá somente de forma direta, mas, também, de forma indireta via condição socioeconômica, a qual poderá potencializar tal efeito, pois, espera-se que níveis de escolaridade mais elevados estejam associados a melhores níveis de renda e, consequentemente, maior será o desempenho escolar dos filhos.

\section{Metodologia}

\subsection{Base de Dados}

Com o intuito de avaliar os efeitos da educação dos pais sobre o desempenho dos filhos no sistema de ensino público brasileiro, serão utilizadas informações referentes às características individuais dos alunos e de sua família, além das condições socioeconômicas da escola a qual estes frequentam. Tais informações foram extraídas do SAEB, Censo Escolar e da Plataforma de Indicadores Sociais disponibilizadas pelo INEP, para o ano de 2015.

A amostra utilizada foi dividida em cinco subamostras, de acordo com as regiões brasileiras, restringindo o estudo apenas para estudantes da área urbana de escolas públicas. Além do mais, a mesma foi separada por gênero a fim de comparar os possíveis efeitos entre homens e mulheres nas diferentes regiões do país.

\subsection{Metodologia Econométrica}

\section{Efeito Mediação}

O objetivo central da estimação de causalidade reside em mensurar o impacto causal de um determinado tratamento sobre o resultado potencial. Entretanto, a obtenção de tal estimativa não fornece informações adicionais a respeito da construção de tais efeitos, além do caminho percorrido pela variável de tratamento até afetar os resultados potenciais. Esse é o objetivo da análise de mediação causal, estimar como o tratamento $(\mathrm{T})$ afeta causalmente o valor 
de resultado (Y) via mediação de uma variável intermediária (M), na qual, encontra-se na via causal entre o tratamento e a variável de resultado.

Nas ciências sociais a análise de mediação causal foi formulada e aplicada na tabela de modelos de equações estruturais lineares, havendo dificuldades na ampliação de tal definição para uma estrutura de modelos não lineares. Ademais, estimar tal efeito por meio de equações estruturais lineares mostrava-se problemático devido à incapacidade de especificar a suposição de identificação chave e também, por conta da existência de uma interdependência de tais resultados a um modelo estatístico específico. Diante de tais limitações, Imai et al. (2010) desenvolveram uma abordagem alternativa e geral para a análise de mediação causal, generalizando-a para modelos tanto lineares quanto não-lineares, paramétricos e não paramétricos. Além do mais, tal generalização é estendida para mediadores contínuos e discretos. Vale salientar também que os autores estenderam a análise de mediação causal para a estrutura contrafactual, independentemente de um modelo estatístico específico.

\section{Abordagem Contrafactual da Educação dos Pais sobre o Rendimento Escolar dos Filhos}

Na tabela contrafactual, a estimativa causal da educação dos pais sobre o desempenho escolar dos filhos é obtida por meio da diferença entre dois resultados acadêmicos possíveis: o primeiro que seria obtido caso a criança tivesse pai (mãe) com determinado nível de instrução (tratados), e o segundo, caso esta tivesse pai (mãe) com escolaridade abaixo do observado no primeiro caso (controle). Diante disso, serão criados dois grupos, o de tratados e não tratados.

Formalizado as informações mencionadas, considere uma amostra composta por $n$ observações retiradas de uma população de $N$ observações com $n \leq N$. Seja $T_{i}$ a variável indicadora de tratamento para o aluno $i$, com valor igual a um se o aluno pertencer ao grupo de tratados e, zero caso contrário. A variável de resultado potencial é dada por $Y_{i(t)}$, em que, $Y_{i(1)}$, e $Y_{i(0)}$, correspondem às proficiências em Português e Matemática que seriam observadas caso o aluno fosse tratado e caso não fosse tratado, respectivamente. Dessa forma, os possíveis resultados entre tratados e não tratados pode ser representado por: $Y_{i(t)}=T_{i} Y_{i(1)}+\left(1-T_{i}\right) Y_{i(0)}$. Entretanto, como não há informações a respeito do desempenho escolar de alunos nas condições, de tratamento e não tratamento, simultaneamente, se $Y_{i(1)}$ for ocorrer $Y_{i(0)}$ não será observado para o indivíduo $i$.

Diante do exposto, o efeito causal da educação dos pais sobre o sucesso escolar dos filhos é dado pela diferença entre $Y_{i(1)}$ e $Y_{i(0)}$ para cada $i$. Entretanto, as possíveis inferências de causalidade para a população são obtidas a partir do efeito médio causal definido como $E\left[Y_{i(1)}-Y_{i(0)}\right]$. Vale salientar também que, se o tratamento for randomizado $Y_{i(t)} \perp T_{i}$, em que, $t=0,1$, o efeito médio causal pode ser obtido como se segue:

$$
\begin{aligned}
E\left[Y_{i(1)}-Y_{i(0)}\right]= & E\left[Y_{i(1)} I T_{i}=1\right]-E\left[Y_{i(1)} I T_{i}=0\right]= \\
& E\left[Y_{i} I T_{i}=1\right]-E\left[Y_{i} I T_{i}=0\right]
\end{aligned}
$$




\section{Efeitos Causais da Educação dos Pais via Mediação das Condições Socioeconômicas}

O objetivo central desta pesquisa reside em demonstrar como a escolaridade dos pais influencia causalmente o rendimento acadêmico dos filhos por meio de uma variável mediadora que se encontra na via de causalidade entre a educação dos pais e o desempenho dos filhos, sendo que esta é afetada pela variável de tratamento antes mesmo de influenciar os resultados potenciais. Neste estudo, a variável mediadora considerada será o nível socioeconômico da família, pois, espera-se que maiores níveis de instrução dos pais estejam associados a melhores condições socioeconômicas, aumentando-se as disponibilidades financeiras para investir na educação dos filhos.

Diante de uma análise de mediação causal, a variável de resultado é função não apenas da condição de tratamento, mas também, da variável mediadora, isto é, $Y_{i}\left(T_{i}, M_{i}\right)$, em que, $M_{i}$ é o mediador entre o tratamento e o resultado potencial. Desse modo, o efeito de mediação causal, também conhecido como efeito indireto, é dado pela diferença entre dois possíveis resultados: o desempenho escolar que seria observado na condição $t$ (tratamento ou de controle), dado o nível socioeconômico observado na condição de tratamento e o resultado que seria obtido pelo mesmo indivíduo na mesma condição $t$ (tratado ou não tratado), porém, com nível socioeconômico que este teria caso estivesse na condição de não tratamento:

$$
\delta_{i(t)} \equiv Y_{i}\left(t, M_{i(1)}\right)-Y_{i}\left(t, M_{i(0)}\right)
$$

O resultado $\delta_{i(1)}$ corresponde a diferença de rendimento acadêmico quando a criança possuiu determinado tratamento (pai ou mãe com determinado nível de escolaridade). Dado $\delta_{i(1)}$, temos que, $Y_{i}\left(1, M_{i(1)}\right)$ diz respeito ao desempenho escolar dos filhos caso estes tenham pais com um dos tratamentos definidos neste estudo (fundamental, médio, superior completos) e, $Y_{i}\left(1, M_{i(0)}\right)$ representa o rendimento escolar dos filhos que seria observado caso estes tenham sido tratados, porém, com uma situação socioeconômica familiar caso este estivesse na situação de não tratamento. Dessa forma, percebe-se que, na estimação do efeito de mediação causal, o mediador varia enquanto que o tratamento é mantido constante de modo a responder a seguinte pergunta: o que aconteceria com o rendimento acadêmico da criança que possui pai (mãe) com ensino médio completo caso esta tivesse o mesmo nível socioeconômico de uma criança com pai (mãe) com ensino médio incompleto?

Diferentemente da mediação causal, no efeito causal direto, a variável de tratamento varia enquanto que o mediador é mantido constante, isto é, fixado para determinada condição de tratamento ou controle. Tal efeito é definido da seguinte forma:

$$
\zeta_{i(t)} \equiv Y_{i}\left(1, M_{i(t)}\right)-Y_{i}\left(0, M_{i(t)}\right)
$$

Diante disso, $\zeta_{i(t)}$ corresponde ao efeito direto da educação dos pais sobre o desempenho dos filhos, mantido constante o nível socioeconômico da família. $Y_{i}\left(1, M_{i(1)}\right)$ representa o rendimento escolar da criança com determinado tratamento, enquanto que, $Y_{i}\left(0, M_{(i(1)}\right)$ diz respeito ao resultado que uma criança com a ausência de tal tratamento teria caso a mesma tivesse o mesmo nível socioeconômico da condição de tratado. 
Uma vez obtidos os efeitos direto e indireto, podemos então obter o efeito tratamento causal total para cada unidade $i$, definido como se segue:

$$
\tau_{i(t)} \equiv Y_{i}\left(1, M_{i(1)}\right)-Y_{i}\left(0, M_{i(0)}\right)=\frac{1}{2} \sum_{t=0}^{1}\left\{\delta_{i(t)}+\zeta_{i(t)}\right\}
$$

Dessa forma, percebe-se que, o efeito causal total pode ser particionado em efeito direto e indireto, destacando que, um efeito total de tratamento igual a zero não necessariamente implica que o tratamento não tem efeito sobre os resultados, pois, é possível que os efeitos direto e indireto tenham a mesma magnitude, com sinais opostos, gerando, assim, um efeito total nulo. Ademais, ao assumir a hipótese de que tanto o efeito direto quanto o indireto são invariantes em relação ao estado de tratamento, $\delta_{i(t)}=\delta_{i(1)}=\delta_{i(0)} \mathrm{e}$ $\zeta_{i(t)}=\zeta_{i(1)}=\zeta_{i(0)}$, caso em que não há efeito de mediação causal, o efeito total será definido como a soma dos dois efeitos causais, já que, sob esta hipótese, o efeito do tratamento total causal não se altera diante de modificações na variável mediadora.

$$
Y_{i}\left(1, M_{i(1)}\right)-Y_{i}\left(0, M_{i(1)}\right)=Y_{i}\left(1, M_{i(0)}\right)-Y_{i}\left(0, M_{i(0)}\right)
$$

Com base no que já foi exposto, podemos definir o efeito médio de mediação causal, estimativa de maior interesse neste estudo, da seguinte forma:

$$
\bar{\delta}_{i(t)} \equiv E\left[Y_{i}\left(t, M_{i(1)}\right)-Y_{i}\left(t, M_{i(0)}\right)\right]
$$

\section{Ignorabilidade Sequencial}

Seja $X_{i}$ o vetor de variáveis de pré-tratamento para cada unidade $i$ em que $\mathcal{X}$ corresponde ao suporte à distribuição das variáveis de pré-tratamento. Neste estudo, $X_{i}$ é caracterizado pelas características individuais e familiares das crianças além das informações a respeito da escola que a mesma frequenta. Diante disso, a hipótese de ignorabilidade sequencial, que depende de outras duas de independência condicional, pode ser escrita como:

$$
\begin{gathered}
\left\{Y_{i}\left(t^{\prime}, m\right), M_{i(t)}\right\} \perp T_{i} \mid X_{i}=x_{i}, \\
Y_{i}\left(t^{\prime}, m\right) \perp M_{i(t)} \mid T_{i}=t, X_{i}=x_{i},
\end{gathered}
$$

em que, $0<\operatorname{Pr}\left(T_{i}=t \mid X_{i}=x\right)$ e $0<p\left(M_{i(t)}=m\left|T_{i}=t\right| X_{i}=x\right)$ para $t=0$, 1 , e para todo $x \in \mathcal{X}$ e $m \in \mathcal{M}$.

Percebe-se que a ignorabilidade é feita de forma sequencial, ou seja, em (7) o tratamento é independente dos resultados potenciais, os quais são função da atribuição de tratamento e do mediador, dada as covariadas de prétratamento. Já em (8), o mediador é independente dos resultados quando condicionado à condição de tratamento e às covariadas de pré-tratamento.

\section{Identificação não Paramétrica sob Ignorabilidade Sequencial}

A identificação não paramétrica garante a consistência das estimativas causais da análise de mediação, independentemente de suposições adicionais de 
forma distributiva ou funcional, o que permite uma generalização da estimação do efeito médio de mediação causal. Sob a hipótese de ignorabilidade sequencial tem-se que

$$
\begin{gathered}
f\left(Y_{i}\left(t, M_{i\left(t^{\prime}\right)}\right) \mid X_{i}=x\right)=\int_{\mathcal{M}} f\left(Y_{i} \mid M_{i(t)}=m, T_{i}=t, X_{i}=x\right) \\
d F_{M_{i}}\left(T_{i}=t^{\prime}, X_{i}=x\right)
\end{gathered}
$$

Para todo $x \in \mathcal{X}$ e $t, t^{\prime}=0,1$.

Desse modo, temos que, sob a hipótese de ignorabilidade sequencial, a distribuição dos resultados potenciais (desempenho em Português ou Matemática) pode ser escrita como função das distribuições das variáveis observadas, $M_{i(t)} \mid\left(T_{i}, X_{i}\right)$ e de $Y_{i} \mid\left(M_{i(t)}, T_{i}, X_{i}\right)$. Ademais, tal suposição permite inferir a respeito das estimativas contrafactuais não observadas a partir das informações observadas.

\subsection{Variáveis Utilizadas no Modelo}

A Tabela 3 apresenta a descrição das variáveis que serão utilizadas no modelo econométrico. As variáveis de tratamento utilizadas referem-se ao nível de instrução dos pais, os quais foram divididos em três níveis de escolaridade: ensinos fundamental, médio e superior. Ressalta-se também que foram criados dois grupos para cada um dos três estratos educacionais dos pais. O primeiro é caracterizado por filhos de pais com determinado nível de escolaridade (tratados), já o segundo, chamado grupo de controle, é composto por aqueles que possuem pais com nível de educação abaixo daquele definido no primeiro grupo. Por exemplo, se a variável de tratamento for ensino médio, então o grupo de tratados é composto por aqueles alunos cujos pais possuem ensino médio completo e, o grupo de controle será caracterizado por aqueles alunos que possuem pais com nível educacional abaixo do ensino médio (médio incompleto, fundamental completo e incompleto, e analfabeto), excluindo-se, assim, de ambos os grupos, tratados e controle, para essa variável de tratamento (ensino médio), alunos cujos pais possuem ensino superior.

O Índice de Condição Socioeconômica da Família foi obtido a partir da análise de componentes principais que engloba os itens descritos na Tabela 2, com seus respectivos pesos, baseados no Critério de Classificação Econômica Brasil (CCEB) da Associação Brasileira de Empresas de Pesquisa (ABEP) de 2014. No Apêndice Apêndice A, encontram-se a metodologia e a matriz dos componentes utilizados para a construção do índice em que este foi padronizado no intervalo entre zero e um, de modo que quanto mais próximo de um estiver o índice, melhor será o nível socioeconômico do aluno e, para valores próximos de zero, o contrário é verificado.

O Índice de Infraestrutura da Escola foi obtido a partir da análise de componentes principais considerando-se as seguintes variáveis: abastecimento de água da rede pública; existência de esgoto sanitário da rede pública; coleta periódica de lixo; sala de diretoria; sala de professores; laboratório de informática; laboratório de ciências; quadra de esportes coberta ou descoberta; cozinha; biblioteca; parque infantil; banheiro adequado para alunos com deficiência; vias adequadas para alunos com deficiência; aparelho de televisão; 
Tabela 1: Descrição das variáveis

\begin{tabular}{|c|c|}
\hline Variáveis & Descrição \\
\hline \multicolumn{2}{|l|}{ Dependentes } \\
\hline Prof. LP & Desempenho em Língua Portuguesa \\
\hline Prof. Mat. & Desempenho em Matemática \\
\hline \multicolumn{2}{|l|}{ Perfil do Aluno } \\
\hline Sexo & $1=$ se masculino; 0 = c.c. \\
\hline Raça & $1=$ se branca; 0 = c.c. \\
\hline Idade $^{1}$ & $\begin{array}{l}1=\text { se a criança está na idade certa para } \\
\text { frequentar o } 5^{\circ} \text { ano; } 0=\text { c.c. }\end{array}$ \\
\hline Reprovação & $1=$ se já reprovou; $0=$ c.c. \\
\hline Abandono Escola & $1=$ se já abandonou a escola alguma vez; $0=$ c.c. \\
\hline Dever Casa1 & $1=$ se faz o dever de casa de Português; 0 = c.c. \\
\hline Dever Casa2 & $1=$ se faz o dever de casa de Matemática; 0 = c.c. \\
\hline Trabalha & $1=$ se a criança trabalha fora de casa; $0=$ c.c. \\
\hline Leitura & $1=$ se a criança lê com frequência; $0=$ c.c. \\
\hline Computador & $1=$ se tem computador em casa; 0 = c.c. \\
\hline \multicolumn{2}{|c|}{ Características da Família } \\
\hline Pai/Mãe & $1=$ se a criança mora com o pai e com a mãe; $0=$ c.c. \\
\hline Incentivo Escola & $1=$ se os pais incentivam a criança a ir à escola; $0=$ c.c. \\
\hline \multicolumn{2}{|l|}{ Tratamentos } \\
\hline Educação Pai1 & $\begin{array}{l}1=\text { pai com fundamental completo; } 0=\text { pai com escolaridade } \\
\text { inferior ao fundamental completo; }\end{array}$ \\
\hline Educação Pai2 & $\begin{array}{l}1 \text { = pai com ensino médio completo; } 0=\text { pai com escolaridade } \\
\text { inferior ao médio completo }\end{array}$ \\
\hline Educação Pai3 & $\begin{array}{l}1=\text { pai com ensino superior completo; } 0=\text { pai com escolaridade } \\
\text { inferior ao superior completo }\end{array}$ \\
\hline Educação Mãe1 & $\begin{array}{l}1=\text { mãe com fundamental completo; } 0=\text { mãe com escolaridade } \\
\text { inferior ao fundamental completo; }\end{array}$ \\
\hline Educação Mãe2 & $\begin{array}{l}1=\text { mãe com ensino médio completo; } 0=\text { mãe com escolaridade } \\
\text { inferior ao médio completo; }\end{array}$ \\
\hline Educação Mãe3 & $\begin{array}{l}1=\text { mãe com ensino superior completo; } 0=\text { mãe com escolaridade } \\
\text { inferior ao superior completo; }\end{array}$ \\
\hline \multicolumn{2}{|l|}{ Mediador } \\
\hline ICSF & Índice de Condição Socioeconômica da Família \\
\hline \multicolumn{2}{|c|}{ Características da Escola } \\
\hline IIE & Índice de Infraestrutura da Escola \\
\hline IAFD & Índice de Adequação da Formação Docente \\
\hline
\end{tabular}


Tabela 2: Itens utilizados na criação do Índice de Condição Socioeconômica da Família

\begin{tabular}{l|c|c|c|c|c|c}
\hline \multirow{2}{*}{\multicolumn{1}{c|}{ Itens }} & \multicolumn{5}{c}{ Quantidade de } \\
& \multicolumn{1}{c}{ Itens e Pontos } \\
\cline { 2 - 6 } & $\mathbf{0}$ & $\mathbf{1}$ & $\mathbf{2}$ & $\mathbf{3}$ & $\mathbf{4}$ ou + \\
\hline Televisor em cores & 0 & 1 & 2 & 3 & 4 \\
\hline Rádio & 0 & 1 & 2 & 3 & 4 \\
\hline Banheiro & 0 & 4 & 5 & 6 & 7 \\
\hline Automóvel & 0 & 4 & 7 & 9 & 9 \\
\hline Empregada mensalista & 0 & 3 & 4 & 4 & 4 \\
\hline Máquina de lavar & 0 & 2 & 2 & 2 & 2 \\
\hline Videocassete e/ou DVD & 0 & 2 & 2 & 2 & 2 \\
\hline Geladeira & 0 & 4 & 4 & 4 & 4 \\
\hline $\begin{array}{l}\text { Freezer (aparelho independente } \\
\text { ou parte da geladeira duplex) }\end{array}$ & 0 & 2 & 2 & 2 & 2 \\
\hline
\end{tabular}

Fonte: Elaboração própria a partir do Índice ABEP (2014).

videocassete; DVD; antena parabólica; copiadora; retroprojetor; impressora; computador; internet e alimentação escolar. Tais informações foram retiradas do Censo Escolar de 2015.

Por fim, o Índice de Adequação da Formação Docente, obtido por meio dos Indicadores Educacionais, corresponde ao percentual de docentes com formação superior de licenciatura ou complementação pedagógica na mesma área da disciplina que leciona.

\section{Análise dos Resultados}

\subsection{Estatísticas Descritivas Condicionadas aos Níveis de Educação dos Pais}

As estatísticas descritivas das variáveis proficiências e Índice de Condição Socioeconômica condicionados ao nível de escolaridade dos pais, para cada região do país, fazendo distinção de gênero, estão explicitadas na Tabela 3. O desempenho escolar tanto em Matemática quanto em Português, quando condicionado à escolaridade dos pais, varia significativamente entre gêneros e regiões. Para todas as regiões do país, as pessoas do sexo feminino, em média, apresentam melhor desempenho em Português, quando comparadas aos homens. Entretanto, em Matemática, o contrário é verificado. O melhor desempenho acadêmico, quando condicionado à escolaridade dos pais, ocorre na Região Sudeste, exceto para o extremo superior da distribuição de escolaridade dos pais, pois, condicionando o rendimento dos alunos a esse nível (ensino superior), a Região Sul apresenta melhores índices. Ressalta-se também que a Região Nordeste registrou o menor rendimento acadêmico por gênero, em todas as categorias de escolaridade dos pais.

A partir da análise descritiva constata-se também que, em todos os estratos de educação dos pais e regiões do Brasil, em média, pais mais escolarizados possuem filhos com melhores desempenhos.

O maior e menor diferencial de desempenho em Língua Portuguesa, entre os grupos tratados e controle, em favor do primeiro, no estrato inferior de edu- 
cação do pai (ensino fundamental completo) foram registrados pelas regiões Norte $(3,6 \%)$ e Sudeste $(1,7 \%)$, respectivamente, e nas regiões Norte $(5,2 \%)$ e Sudeste $(1,0 \%)$, respectivamente, para o extremo superior da distribuição de escolaridade do pai (ensino superior completo); em Matemática, encontramse, respectivamente, o Norte $(3,2 \%)$ e as regiões Sul e Sudeste com diferencial de $2,0 \%$ em favor das crianças que possuem pai com ensino fundamental completo e, para o estrato superior, as regiões Norte $(4,5 \%)$ e Sudeste $(1,0 \%)$, respectivamente.

Para filhos do sexo feminino, os maiores e menores hiatos de desempenho em Português encontram-se nas regiões Norte/Nordeste $(3,2 \%)$ e Sudeste $(2,3 \%)$, respectivamente, para a distribuição inferior de educação do pai, enquanto que, para a superior, encontram-se as regiões Norte $(3,1 \%)$ e Sudeste $(0,83 \%)$, respectivamente; em Matemática, os maiores e menores hiatos de desempenhos em favor dos tratados encontram-se nas regiões Centro-Oeste $(2,9 \%)$ e Sul/Sudeste $(2,0 \%)$, respectivamente, para o extremo inferior e, Norte $(3,1 \%)$ e Sudeste $(0,88 \%)$, respectivamente, para o superior.

No que diz respeito à escolaridade da mãe, os maiores e menores desempenho em Português, em favor dos filhos tratados, foram verificados nas regiões Norte $(6,2 \%)$ e Centro-Oeste $(3,3 \%)$, respectivamente, para o extremo inferior de educação da mãe (fundamental completo) e, para o Norte $(6,1 \%)$ e Sudeste $(1,9 \%)$, para o nível de ensino superior, respectivamente; em Matemática, encontram-se as regiões Norte e Sudeste com magnitude de 5,3\% e 3,4\%, respectivamente, para o estrato inferior e, 5,4\% e 1,7\%, para a categoria de ensino superior, respectivamente.

Em relação às filhas, para o extremo inferior da distribuição de educação, as maiores e menores diferenças na proficiência de Português encontra-se nas regiões Norte $(6,6 \%)$ e Sul $(3,9 \%)$ e, em Norte $(4,4 \%)$ e Sudeste $(1,7 \%)$, para o extremo superior, respectivamente; na disciplina de Matemática, os maiores e menores diferenciais estão presentes nas regiões Norte $(5,5 \%)$ e Sudeste $(3,7 \%)$, respectivamente, em favor das filhas que possuem mãe com ensino fundamental completo, quando comparadas àquelas com nível de escolaridade inferior a esta. Para as filhas de mãe com ensino superior completo (tratados) em comparação àquelas com pais abaixo desse nível de educação (controle), os maiores e menores diferenciais encontram-se nas regiões Norte e Nordeste, com magnitude de $3,9 \%$ e $1,4 \%$ em favor dos tratados, respectivamente.

A análise descritiva dos dados também releva que, maiores níveis socioeconômicos da família estão associados a melhores resultados escolares dos filhos, para as duas disciplinas analisadas. Além disso, verifica-se que, em média, estratos mais elevados de educação dos pais estão associados a maiores níveis socioeconômicos, o que indica que, há uma associação positiva entre educação dos pais e condição socioeconômica familiar, já que, pais mais escolarizados estão mais propensos a adquirir maiores níveis de renda.

\subsection{Resultados Econométricos}

Conclusões a respeito do efeito causal da educação dos pais sobre o rendimento escolar de seus filhos não são sustentáveis a partir de uma simples comparação de resultados entre as crianças tratadas e não tratadas, pois devese isolar os efeitos da educação dos pais de outros fatores que possam influenciar os resultados potenciais. Visando isolar tais efeitos, e estimar os reais 
Tabela 3: Estatística descritiva dos dados condicionados aos níveis de escolaridade dos pais

\begin{tabular}{|c|c|c|c|c|c|c|c|c|c|c|c|c|}
\hline \multicolumn{13}{|c|}{ Região Norte } \\
\hline \multirow{3}{*}{ Variáveis } & \multicolumn{6}{|c|}{$\begin{array}{c}\text { Tratamento: Educação do Pai } \\
\end{array}$} & \multicolumn{6}{|c|}{$\begin{array}{l}\text { Tratamento: Educação da Mãe } \\
\end{array}$} \\
\hline & \multicolumn{2}{|c|}{ Fundamental Completo } & \multicolumn{2}{|c|}{ Médio Completo } & \multicolumn{2}{|c|}{ Superior Completo } & \multicolumn{2}{|c|}{ Fundamental Completo } & \multicolumn{2}{|c|}{ Médio Completo } & \multicolumn{2}{|c|}{ Superior } \\
\hline & Tratados & Controle & Tratados & Controle & Tratados & Controle & Tratados & Controle & Tratados & Controle & Tratados & Controle \\
\hline Nota LP & $(0,2250)$ & $(0,2)$ & $(0,2089)$ & $(0,2254)$ & $(0,2141)$ & $(0,2269)$ & 26) & $(0,2224)$ & $(0,2$ & $(0,2242)$ & 149) & $(0,2263)$ \\
\hline Nota Mat. & 212,9038 & 206,2879 & 229,9835 & 208,2518 & 224,1258 & 214,5184 & 212,9542 & 202,2208 & 229,7519 & 205,4872 & 225,4454 & 213,9654 \\
\hline Nota Mat. & $(0,2081)$ & $(0,2048)$ & $(0,1939)$ & $(0,2063)$ & $(0,2006)$ & & $(0,2035)$ & $(0,2019)$ & $(0,1940)$ & $(0,2039)$ & $(0,1999)$ & \\
\hline ICSF & 0,5115 & 0,4884 & 0,5402 & 0,4927 & 0,5579 & 0,4982 & 0,50507 & 0,4845 & 0,5355 & 0,4882 & 0,5627 & 0,4959 \\
\hline \multicolumn{13}{|c|}{ Filhas } \\
\hline Nota LP & $\begin{array}{r}208,7203 \\
(0,2149)\end{array}$ & $\begin{array}{c}202,1399 \\
(0,2140)\end{array}$ & $\begin{array}{c}224,9209 \\
(0,1944)\end{array}$ & $\begin{array}{r}204,1469 \\
(0,2148)\end{array}$ & $\begin{array}{r}217,7134 \\
(0,2057)\end{array}$ & $\begin{array}{r}211,2592 \\
(0,2125)\end{array}$ & $\begin{array}{c}209,9133 \\
(0,2127)\end{array}$ & $\begin{array}{r}196,8870 \\
(0,2132)\end{array}$ & $\begin{array}{r}224,7512 \\
(0,1907)\end{array}$ & $\begin{array}{c}200,9094 \\
(0,2152)\end{array}$ & $\begin{array}{c}219,8862 \\
(0,2058)\end{array}$ & $\begin{array}{c}210,6646 \\
(0,2119)\end{array}$ \\
\hline & 212,5463 & 206,8821 & 225,5185 & 208,6097 & 219,5279 & 214,3987 & 213,1573 & 201,9802 & 225,6321 & 205,4316 & 222,0421 & 213,6969 \\
\hline Nota Ma & $(0,1964)$ & $(0,1994)$ & $(0,1889)$ & $(0,1988)$ & $(0,2003)$ & $(0,1989)$ & $(0,2001)$ & $(0,1942)$ & $(0,1861)$ & $(0,1978)$ & $(0,2004)$ & \\
\hline ICSF & 0,5086 & 0,4866 & 0,5305 & 0,4907 & 0,5628 & 0,4960 & 0,5099 & 0,4826 & 0,5260 & 0,4885 & 0,5677 & 0,4950 \\
\hline & $(0,2060)$ & & $(0,1995)$ & & $(0,2163)$ & & $(0,2017)$ & 87) & & $(0,2241)$ & $(0,2116)$ & $(0,2216)$ \\
\hline \multicolumn{13}{|c|}{ Filhos } \\
\hline & & & & & & & & & & & & \\
\hline ICSF & $(0,2036)$ & $(0,22$ & $(0,2011)$ & $(0,2263)$ & $\begin{array}{l}0,04314 \\
(0,2151)\end{array}$ & & $\begin{array}{l}0,5104 \\
(0,2060)\end{array}$ & $\begin{array}{c}0,4834 \\
(0,2301)\end{array}$ & $\begin{array}{l}0,5262 \\
(0,1964)\end{array}$ & $\begin{array}{l}0,4865 \\
(0,2283)\end{array}$ & $\begin{array}{c}0,5498 \\
(0,2118)\end{array}$ & $\begin{array}{c}0,4869 \\
(0,2278)\end{array}$ \\
\hline$N$ & 4973 & 15562 & 5087 & 20535 & 5244 & 25622 & 4739 & 14434 & 6347 & 19173 & 5346 & 25520 \\
\hline \multicolumn{13}{|c|}{ Filhas } \\
\hline Nota LP & $\begin{array}{c}207,7873 \\
(0,2229)\end{array}$ & $\begin{array}{c}201,3274 \\
(0,2274)\end{array}$ & $\begin{array}{r}223,2622 \\
(0,1967)\end{array}$ & $\begin{array}{c}202,8968 \\
(0,2267)\end{array}$ & $\begin{array}{r}210,1216 \\
(0,2109)\end{array}$ & $\begin{array}{r}207,6145 \\
(0,2231)\end{array}$ & $\begin{array}{r}208,1407 \\
(0,2242)\end{array}$ & $\begin{array}{r}199,0163 \\
(0,2265)\end{array}$ & $\begin{array}{r}222,6963 \\
(0,1968)\end{array}$ & $\begin{array}{r}201,3488 \\
(0,2267)\end{array}$ & $\begin{array}{r}211,7979 \\
(0,2125)\end{array}$ & $\begin{array}{r}207,3310 \\
(0,2226)\end{array}$ \\
\hline Nota Mat. & $\begin{array}{r}212,0656 \\
(0,2004)\end{array}$ & $\begin{array}{c}207,1561 \\
(0,2021)\end{array}$ & $\begin{array}{c}223,2451 \\
(0,1875)\end{array}$ & $\begin{array}{r}208,3488 \\
(0,2019)\end{array}$ & $\begin{array}{c}212,0323 \\
(0,1937)\end{array}$ & $\begin{array}{r}211,7996 \\
(0,2006)\end{array}$ & $\begin{array}{c}212,8364 \\
(0,1993)\end{array}$ & $\begin{array}{r}204,7497 \\
(0,2012)\end{array}$ & $\begin{array}{c}223,0812 \\
(0,1865)\end{array}$ & $\begin{array}{r}206,8170 \\
(0,2014)\end{array}$ & $\begin{array}{r}214,3633 \\
(0,1963)\end{array}$ & $\begin{array}{r}211,3746 \\
(0,2000)\end{array}$ \\
\hline ICSF & 0,5092 & 0,4793 & 0,5185 & 0,4829 & 0,5403 & 0,4820 & 0,5049 & 0,4779 & 0,5169 & 0,4810 & 0,5470 & 0,4814 \\
\hline & & & $(0,2022)$ & & $(0,2162)$ & & $(0,2038)$ & & $(0,2014)$ & $(0,2228)$ & $(0,2135)$ & $(0,2243)$ \\
\hline$N$ & 4510 & 14054 & 5597 & 18564 & 4700 & 24161 & 4488 & 13068 & 6835 & 17556 & 4470 & 24391 \\
\hline
\end{tabular}


Tabela 3: Estatística descritiva dos dados condicionados aos níveis de escolaridade dos pais (continuação)

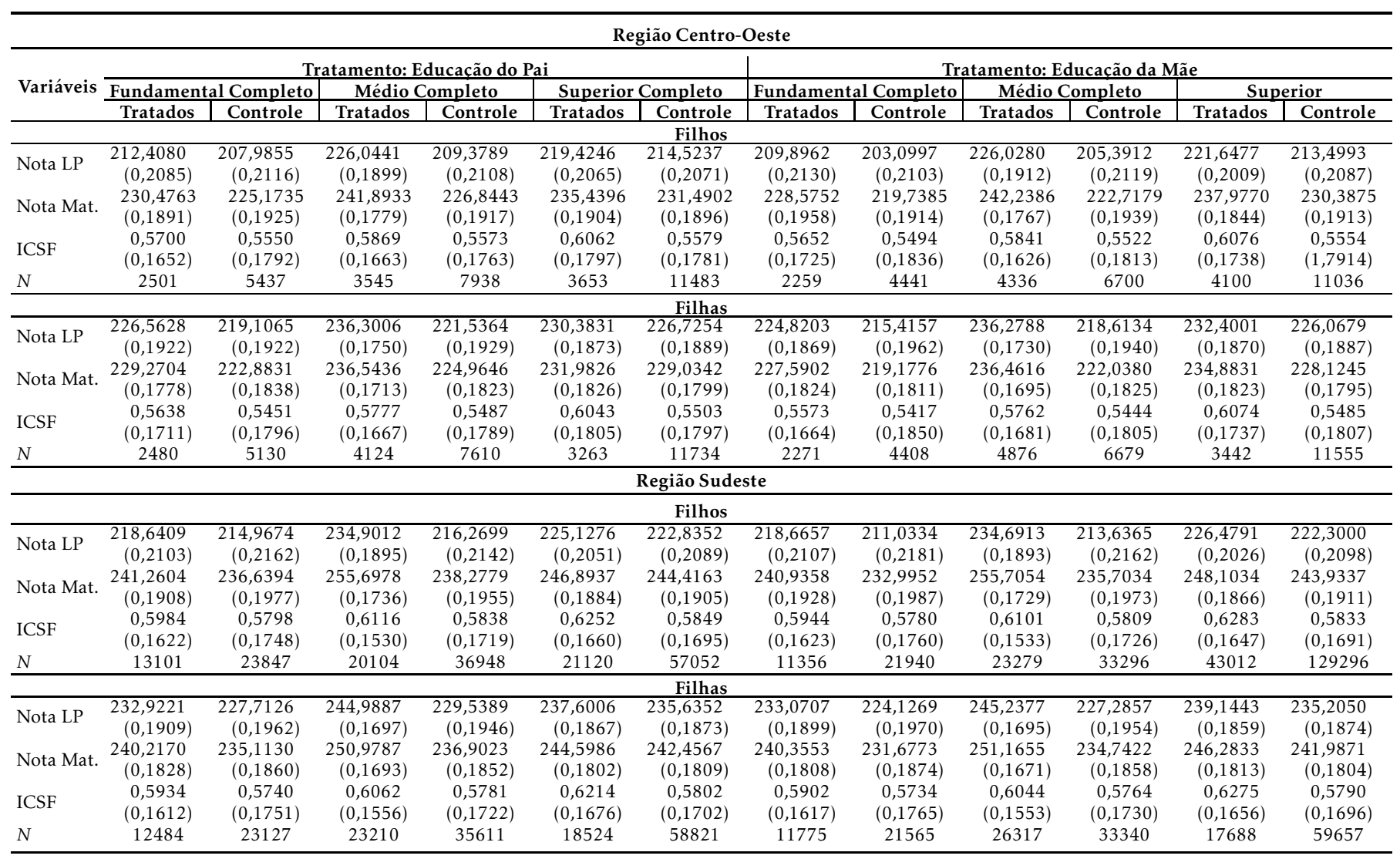


Tabela 3: Estatística descritiva dos dados condicionados aos níveis de escolaridade dos pais (continuação)

\begin{tabular}{|c|c|c|c|c|c|c|c|c|c|c|c|c|}
\hline \multicolumn{13}{|c|}{ Região Sul } \\
\hline \multirow{2}{*}{ Variáveis } & \multicolumn{6}{|c|}{$\begin{array}{l}\text { Tratamento: Educação do Pai } \\
\end{array}$} & \multicolumn{6}{|c|}{\begin{tabular}{|c|} 
Tratamento: Educação da Mãe \\
\end{tabular}} \\
\hline & Tratados & Controle & Tratados & \begin{tabular}{|l|} 
Controle \\
\end{tabular} & Tratados & Controle & Tratados & Controle & Tratados & Controle & Tratados & Controle \\
\hline \multicolumn{13}{|c|}{ Filhos } \\
\hline Nota Mat. & $\begin{array}{r}240,5408 \\
(0,1782)\end{array}$ & $\begin{array}{r}235,9147 \\
(0,1825)\end{array}$ & $\begin{array}{r}251,6576 \\
(0,1650)\end{array}$ & $\begin{array}{r}237,3778 \\
(0,1814)\end{array}$ & $\begin{array}{r}249,5778 \\
(0,1743)\end{array}$ & $\begin{array}{r}241,8612 \\
(0,1782)\end{array}$ & $\begin{array}{r}241,3120 \\
(0,1787)\end{array}$ & $\begin{array}{r}233,0553 \\
(0,1841)\end{array}$ & $\begin{array}{r}251,5803 \\
(0,1645)\end{array}$ & $\begin{array}{r}235,5261 \\
(0,1832)\end{array}$ & $\begin{array}{r}250,8180 \\
(0,1706)\end{array}$ & $\begin{array}{r}241,2448 \\
(0,1791)\end{array}$ \\
\hline ICSF & 0,6170 & 0,6031 & 0,6270 & 0,6049 & 0,6410 & 0,6032 & 0,6113 & 0,5995 & 0,6269 & 0,6003 & 0,64729 & 0,6001 \\
\hline \multicolumn{13}{|c|}{ Filhas } \\
\hline Nota LP & $\begin{array}{c}231,6397 \\
(0,1851)\end{array}$ & $\begin{array}{c}225,6076 \\
(0,1877)\end{array}$ & $\begin{array}{c}243,0541 \\
(0,1687)\end{array}$ & $\begin{array}{c}227,5331 \\
(0,1874)\end{array}$ & $\begin{array}{c}239,8194 \\
(0,1806)\end{array}$ & $\begin{array}{c}232,8992 \\
(0,1834)\end{array}$ & $\begin{array}{c}231,5954 \\
(0,1835)\end{array}$ & $\begin{array}{c}222,9736 \\
(0,1897)\end{array}$ & $\begin{array}{c}243,2389 \\
(0,1658)\end{array}$ & $\begin{array}{r}225,6496 \\
(0,1885)\end{array}$ & $\begin{array}{r}241,4977 \\
(0,1798)\end{array}$ & $\begin{array}{r}232,3260 \\
(0,1833)\end{array}$ \\
\hline Nota Mat. & 238,3761 & $\begin{array}{c}233,0921 \\
(0.1772)\end{array}$ & $\begin{array}{r}247,9729 \\
(0.1620)\end{array}$ & $\begin{array}{c}234,7788 \\
(0.1761)\end{array}$ & $\begin{array}{r}246,0965 \\
(0.1767)\end{array}$ & $\begin{array}{c}239,3404 \\
(0.1731)\end{array}$ & $\begin{array}{c}239,3651 \\
(0.1734)\end{array}$ & $\begin{array}{r}229,9847 \\
(0.1766)\end{array}$ & $\begin{array}{c}248,3581 \\
(0.1611)\end{array}$ & 232,8962 & $\begin{array}{c}247,7932 \\
(01739)\end{array}$ & 238,7651 \\
\hline & $(0,1730)$ & $\begin{array}{c}(0,1772) \\
0,5961\end{array}$ & $\begin{array}{c}(0,1620) \\
0,6215\end{array}$ & $\begin{array}{c}(0,1761) \\
0,5981\end{array}$ & $\begin{array}{c}(0,1767) \\
0,6423\end{array}$ & $\begin{array}{r}(0,17 \\
0,597\end{array}$ & $\begin{array}{c}(0,1734) \\
0,6097\end{array}$ & $\begin{array}{c}(0,1766) \\
0,5936\end{array}$ & $\begin{array}{c}(0,1611) \\
0,6214\end{array}$ & $\begin{array}{c}(0,1766) \\
0,5958\end{array}$ & $\begin{array}{c}(0,1739) \\
0,6454\end{array}$ & $\begin{array}{l}\text { 34) } \\
57\end{array}$ \\
\hline ICSF & $(0,1507)$ & $(0,1588)$ & $(0,1443)$ & $(0,1572)$ & $(0,1578)$ & $(0,1562)$ & $(0,1481)$ & $(0,1605)$ & $(0,1452)$ & & $(0,1536)$ & $(0,1564)$ \\
\hline$N$ & 4919 & 10491 & 8143 & 15410 & 5842 & 23553 & 4458 & 9905 & 8787 & 14363 & 6245 & 23150 \\
\hline
\end{tabular}

Fonte: Elaboração própria. Nota: i) O grupo tratado é caracterizado por filhos de pais com determinado nível de escolaridade, já o segundo,

chamado grupo de controle, é composto por aqueles que possuem pais com nível de educação abaixo daquele definido no primeiro grupo. ii) Os termos entre parênteses referem-se ao coeficiente de variação; iii) $\mathrm{N}$ = número de observações. 
impactos médios da escolaridade dos pais, utilizou-se o método de mediação causal, o qual permite decompor o efeito total da educação dos pais nos efeitos direto e indireto, sendo que, neste último, a educação dos pais afeta o desempenho dos filhos via condição socioeconômica da família. Os resultados das estimativas estão explicitados nas Tabelas 4 e 5.

A partir dos resultados, verifica-se que, o efeito médio de mediação causal via condição socioeconômica da família é positivo e estatisticamente significante em todos os estratos de educação dos pais e regiões do país, para ambas as disciplinas.

As estimativas para ambas as disciplinas, regiões e gêneros, mostram que, o efeito médio de mediação causal ganha força à medida que a educação dos pais aumenta. Tal resultado já era esperado, pois, pais mais escolarizados possuem, em média, melhores condições socioeconômicas, e com isso, potencializa-se o efeito indireto da educação dos mesmos sobre o rendimento escolar dos filhos via condição socioeconômica. Ademais, torna-se importante destacar também que o efeito indireto da educação dos pais, nos níveis mais baixos de escolaridade (fundamental e médio), em média, é expressivamente menor que o efeito direto. Por outro lado, no extremo superior de educação (superior completo), ocorre o contrário, havendo, em média, uma predominância do efeito de mediação causal sobre o rendimento escolar dos filhos, sugerindo que, pais com ensino superior completo possuem maior influência via condição socioeconômica do que, de forma direta, indicando que, o efeito da educação dos pais para o extremo superior da distribuição de escolaridade destes, pode ser superestimado ao desconsiderar o efeito indireto associado ao nível socioeconômico da família, até então, não levado em consideração pela literatura.

Diferentemente do efeito indireto, o efeito direto perde força no extremo superior de escolaridade dos pais (ensino superior completo) e, consequentemente, o mesmo ocorre para o efeito total, já que, para esse mesmo estrato de educação, os efeitos, direto e indireto, variam em sentidos contrários de modo que o primeiro perde força ao ponto ser negativo, em alguns casos, e o segundo ganha força, gerando-se, assim, um efeito total relativamente pequeno.

Em alguns casos, as estimativas apontam para efeitos totais negativos da educação do pai de educação mais elevado. Em relação à mãe, não se observou esse efeito negativo, pois esta apresentou sinal negativo apenas sobre alunos da Região Nordeste, no que diz respeito ao efeito total, para ambas as disciplinas, porém o efeito foi insignificante. Já em relação ao pai com superior completo, este possui impacto total significativamente maior que zero apenas para a Região Sul, tanto em Português quanto em Matemática.

A partir da Tabela 3 verifica-se que a média de desempenho dos grupos tratados (filhos de pai com ensino superior completo) e controle (filhos de pai com escolaridade abaixo do ensino superior), em ambas as disciplinas, são relativamente próximas. Diante disso, mesmo que o desempenho médio dos tratados seja maior, quando comparado ao grupo de controle, este pode se tornar menor, após a eliminação de viés, feita a partir do controle de outras variáveis que possam influenciar o nível de desempenho dos alunos ${ }^{2}$, gerando-

\footnotetext{
${ }^{2}$ Como teste de robustez, para as regiões e grupos (pai com nível superior), onde o impacto causal da variável de tratamento de ensino superior foi negativo, optou-se por fazer uma regressão simples da variável de educação dos pais com ensino superior contra o desempenho escolar, e encontrou-se que o coeficiente da regressão se mostra positivo e significativo. No entanto, após inserir as variáveis de controle, descritas na Tabela 1, a influência da educação dos pais com ní-
} 
Tabela 4: Efeitos direto, indireto e total da escolaridade dos pais para a disciplina de Português

\begin{tabular}{|c|c|c|c|c|c|c|}
\hline \multirow{3}{*}{ Efeitos } & \multicolumn{6}{|c|}{ Região Norte } \\
\hline & \multicolumn{3}{|c|}{$\begin{array}{l}\text { Tratamento: Educacão do Pai } \\
\end{array}$} & \multicolumn{3}{|c|}{ Tratamento: Educação da Mãe } \\
\hline & Fundamental & Médio & Superior & Fundamental & Médio & Superior \\
\hline \multicolumn{7}{|c|}{ Filhos } \\
\hline Efeito Mediação & $\begin{array}{c}0,4103 \\
{[0,2337 ; 0,5962]}\end{array}$ & $\begin{array}{c}0,7088 \\
{[0,4981 ; 0,9229]}\end{array}$ & $\begin{array}{c}0,8761 \\
{[0,6652 ; 1,0870]}\end{array}$ & $\begin{array}{c}0,3419 \\
{[0,1739 ; 0,5265]}\end{array}$ & $\begin{array}{c}0,8878 \\
{[0,6430 ; 1,1376]}\end{array}$ & $\begin{array}{c}1,2982 \\
{[1,0174 ; 1,5796]}\end{array}$ \\
\hline Efeito Direto & $\begin{array}{c}0,4952 \\
{[-1,2941 ; 2,2293]}\end{array}$ & $\begin{array}{c}8,5503 \\
{[6,8475 ; 10,2006]}\end{array}$ & {$[-0,5254$} & $\begin{array}{c}5,6627 \\
{[3,7838 ; 7,4836]}\end{array}$ & $\begin{array}{c}10,7787 \\
{[9,1338 ; 12,3728]}\end{array}$ & $\begin{array}{c}0,7738 \\
{[-0,8076 ; 2,3064]}\end{array}$ \\
\hline Efeito Total & $\begin{array}{c}0,9055 \\
{[-0,8677 ; 2,6388]}\end{array}$ & $\begin{array}{c}9,2591 \\
{[7,5715 ; 10,8993]}\end{array}$ & $\begin{array}{c}0,3507 \\
{[-1,2125 ; 1,8693]}\end{array}$ & $\begin{array}{c}6,0046 \\
{[4,1407 ; 7,8096]}\end{array}$ & $\begin{array}{c}11,6665 \\
{[10,0441 ; 13,2552]}\end{array}$ & $\begin{array}{c}2,0719 \\
{[0,4898 ; 3,6284]}\end{array}$ \\
\hline \multicolumn{7}{|c|}{ Filhas } \\
\hline Efeito Mediação & $\begin{array}{c}0,3403 \\
{[0,1780 ; 0,5180]}\end{array}$ & $\begin{array}{c}0,4377 \\
{[0,2587 ; 0,6255]}\end{array}$ & $\begin{array}{c}0,6816 \\
{[0,4418 ; 0,9151]}\end{array}$ & $\begin{array}{c}0,4794 \\
{[0,2702 ; 0,7051]}\end{array}$ & $\begin{array}{c}0,4981 \\
{[0,3211 ; 0,6819]}\end{array}$ & $\begin{array}{c}0,9139 \\
{[0,6083 ; 1,2029]}\end{array}$ \\
\hline Efeito Direto & $\begin{array}{c}-0,0795 \\
{[-1,9686 ; 1,7513]}\end{array}$ & $\begin{array}{c}7,0254 \\
{[5,3859 ; 8,6143]}\end{array}$ & $\begin{array}{c}-2,9874 \\
{[-4,6424 ;-1,3834]}\end{array}$ & $\begin{array}{c}6,3242 \\
{[4,3085 ; 8,2778]}\end{array}$ & $\begin{array}{c}11,9332 \\
{[10,3354 ; 13,4817]}\end{array}$ & $\begin{array}{c}0,4436 \\
{[-1,2488 ; 2,0840]}\end{array}$ \\
\hline Ffeito : & 0,2608 & 7,4631 & $-2,3058$ & 6,8036 & 12,4313 & 1,3576 \\
\hline Efeito Total & {$[-1,6156 ; 2,0732]$} & {$[5,8372 ; 9,0306]$} & {$[-3,9462 ;-0,7170]$} & {$[4,7987 ; 8,7427]$} & {$[10,8427 ; 13,9656]$} & {$[-0,3262 ; 3,0091]$} \\
\hline \multirow{3}{*}{ Efeitos } & \multicolumn{6}{|c|}{ Região Nordeste } \\
\hline & \multicolumn{3}{|c|}{$\begin{array}{l}\text { Tratamento: Educação do Pai } \\
\end{array}$} & \multicolumn{3}{|c|}{ Tratamento: Educação da Mãe } \\
\hline & Fundamental & Médio & Superior & Fundamental & Médio & Superior \\
\hline \multicolumn{7}{|c|}{ Filhos } \\
\hline Efeito Mediação & $\begin{array}{c}0,2795 \\
{[0,1637 ; 0,4009]}\end{array}$ & $\begin{array}{c}0,2723 \\
{[0,1537 ; 0,3944]}\end{array}$ & $\begin{array}{c}0,3187 \\
{[0,1859 ; 0,4496]}\end{array}$ & $\begin{array}{c}0,2636 \\
{[0,1462 ; 0,3881]}\end{array}$ & $\begin{array}{c}0,3172 \\
{[0,1726 ; 0,4583]}\end{array}$ & $\begin{array}{c}0,5654 \\
{[0,3612 ; 0,7573]}\end{array}$ \\
\hline Efeito Direto & $\begin{array}{c}0,2373 \\
{[-1,1297 ; 1,5622]}\end{array}$ & $\begin{array}{c}8,1115 \\
{[6,7103 ; 9,4695]}\end{array}$ & {$\left[\begin{array}{c}-1,7241 \\
-3,1207 ;-0,3705\end{array}\right.$} & $\begin{array}{c}4,2161 \\
2,8149 ; 5,5741]\end{array}$ & 12,4571 & $\begin{array}{l}-0,9073 \\
{[-2,3109 \cdot 04529]}\end{array}$ \\
\hline & $\begin{array}{c}{[-1,1297 ; 1,5622]} \\
0,5168\end{array}$ & $\begin{array}{c}{[6,7103 ; 9,4695]} \\
8,3838\end{array}$ & $\begin{array}{c}{[-3,1207 ;-0,3705]} \\
-1,4054\end{array}$ & $\begin{array}{c}{[2,8149 ; 5,5 / 41]} \\
4,4798\end{array}$ & $\begin{array}{c}{[11,1513 ; 13,7228]} \\
12,7744\end{array}$ & $\begin{array}{c}{[-2,3109 ; 0,4529]} \\
-0,3419\end{array}$ \\
\hline Efeito Total & {$[-0,8343 ; 1,8227]$} & {$[6,9991 ; 9,7234]$} & {$[-2,7901 ;-0,0695]$} & {$[3,0960 ; 5,8183]$} & {$[11,4793 ; 14,0290]$} & {$[-1,7414 ; 0,9961]$} \\
\hline \multicolumn{7}{|c|}{ Filhas } \\
\hline Efeito Mediação & $\begin{array}{c}0,0935 \\
{[-0,0531 ; 0,2281]}\end{array}$ & $\begin{array}{c}0,0481 \\
{[-0,0723 ; 0,1590]}\end{array}$ & $\begin{array}{c}0,0824 \\
\lceil-0,0851 ; 0,238\end{array}$ & $\begin{array}{c}0,0676 \\
{[-0,0531: 0,1783]}\end{array}$ & $\begin{array}{c}0,0785 \\
{[-0,0572 ; 0,2043]}\end{array}$ & $\begin{array}{c}0,1372 \\
{[-0,0888: 0,3432]}\end{array}$ \\
\hline & {$\left[\begin{array}{c}-0,0031,0,01 \\
1,4747\end{array}\right.$} & $\begin{array}{c}{[-0,0 / 20 ; 0,1390]} \\
9,3412\end{array}$ & $\begin{array}{c}{[-0,0831,20,2082]} \\
-3,2463\end{array}$ & $\begin{array}{c}{[-0,0301 ; 0,1 / 80]} \\
2,8757\end{array}$ & $\begin{array}{c}{[-0,03 / 2 ; 0,2040]} \\
10,4527\end{array}$ & $\begin{array}{c}{[-0,0808 ; 0,3432]} \\
-1,4678\end{array}$ \\
\hline Efeito Direto & {$[0,0226 ; 2,8821]$} & {$[7,9754 ; 10,6649]$} & {$[-4,7047 ;-1,8328]$} & {$[1,3963 ; 4,3095]$} & {$[9,1672 ; 11,6985]$} & {$[-2,9641 ;-0,0176]$} \\
\hline Efeito Total & 1,5683 & 9,3893 & $-3,1638$ & 2,9433 & 10,5312 & $-1,3305$ \\
\hline EIelto lotal & {$[0,1325 ; 2,9585]$} & {$[8,0391 ; 10,7009]$} & {$[-4,6038 ;-1,7668]$} & {$[1,4823 ; 4,3609]$} & {$[9,2578 ; 11,7664]$} & {$[-2,8014 ; 0,1015]$} \\
\hline
\end{tabular}


Tabela 4: Efeitos direto, indireto e total da escolaridade dos pais para a disciplina de Português (continuação)

\begin{tabular}{|c|c|c|c|c|c|c|}
\hline \multirow{3}{*}{ Efeitos } & \multicolumn{6}{|c|}{ Região Centro-Oeste } \\
\hline & \multicolumn{3}{|c|}{ Tratamento: Educação do Pai } & \multicolumn{3}{|c|}{ Tratamento: Educação da Mãe } \\
\hline & Fundamental & Médio & Superior & Fundamental & Médio & Superior \\
\hline \multicolumn{7}{|c|}{ Filhos } \\
\hline Efeito Mediação & $\begin{array}{c}0,3188 \\
{[0,1449 ; 0,5105]}\end{array}$ & $\begin{array}{c}0,4739 \\
{[0,3006 ; 0,6551]}\end{array}$ & $\begin{array}{c}0,7474 \\
{[0,5356 ; 0,9609]}\end{array}$ & $\begin{array}{c}0,5082 \\
{[0,2605 ; 0,7772]}\end{array}$ & $\begin{array}{c}0,6798 \\
{[0,4663 ; 0,8981]}\end{array}$ & $\begin{array}{c}1,0265 \\
{[0,7616 ; 1,2946]}\end{array}$ \\
\hline Efeito Direto & $\begin{array}{c}0,0349 \\
{[-1,9352 ; 1,9442]}\end{array}$ & $\begin{array}{c}6,6930 \\
{[4,9403 ; 8,3917]}\end{array}$ & {$\left[\begin{array}{c}-3,2274 \\
{[-4,9463 ;-1,5615]}\end{array}\right.$} & $\begin{array}{c}3,0588 \\
{[0,9486 ; 5,1040]}\end{array}$ & $\begin{array}{c}11,3754 \\
{[9,6405 ; 13,0568]}\end{array}$ & $\begin{array}{c}1,4311 \\
{[-0,2442 ; 3,0549]}\end{array}$ \\
\hline Efeito Total & $\begin{array}{c}0,3537 \\
-1.5995 \cdot 2,2420\end{array}$ & $\begin{array}{c}7,1670 \\
\end{array}$ & $\begin{array}{c}-2,4800 \\
-41827 \cdot-0,83200\end{array}$ & 3,5671 & $\begin{array}{c}12,0552 \\
1366 \cdot 13\end{array}$ & 2,4576 \\
\hline \multicolumn{7}{|c|}{ Filhas } \\
\hline Efeito Mediação & $\begin{array}{c}0,2121 \\
{[0,0668 ; 0,3731]}\end{array}$ & $\begin{array}{c}0,2855 \\
{[0,1437 ; 0,4363]}\end{array}$ & $\begin{array}{c}0,4866 \\
{[0,2573 ; 0,7067]}\end{array}$ & $\begin{array}{c}0,1662 \\
{[0,0467 ; 0,3130]}\end{array}$ & $\begin{array}{c}0,3379 \\
{[0,1615 ; 0,5171]}\end{array}$ & $\begin{array}{c}0,6491 \\
{[0,3648 ; 0,9176]}\end{array}$ \\
\hline Efeito Direto & 2,3801 & 6,1765 & $-2,4895$ & $\begin{array}{c}5,5558 \\
3,4699 \cdot 7\end{array}$ & $\begin{array}{c}10,5761 \\
88548 \cdot 12\end{array}$ & 0,4202 \\
\hline & $\begin{array}{c}{[0,4192 ; 4,2804]} \\
2,5922\end{array}$ & $\begin{array}{c}{[4,5305 ; 7,7717]} \\
6,4620\end{array}$ & $\begin{array}{c}{[-4,2312 ;-0,8015]} \\
-2,0029\end{array}$ & $\begin{array}{c}{[3,4699 ; 7,5774]} \\
5,7221\end{array}$ & $\begin{array}{c}{[8,9548 ; 12,1474]} \\
10,9140\end{array}$ & $\begin{array}{c}{[-1,3096 ; 2,0967]} \\
1,0693\end{array}$ \\
\hline Efeito Total & {$[0,6531 ; 4,4715]$} & {$[4,8342 ; 8,0326]$} & {$[-3,7326 ;-0,3457]$} & {$[3,6425 ; 7,7281]$} & {$[9,3091 ; 12,4669]$} & {$[-0,6417 ; 2,7296]$} \\
\hline \multirow{3}{*}{ Efeitos } & \multicolumn{6}{|c|}{ Região Sudeste } \\
\hline & \multicolumn{3}{|c|}{ Tratamento: Educação do Pai } & \multicolumn{3}{|c|}{ Tratamento: Educação da Mãe } \\
\hline & Fundamental & Médio & Superior & Fundamental & Médio & Superior \\
\hline \multicolumn{7}{|c|}{ Filhos } \\
\hline & 0,3520 & 0,3168 & 0,4460 & 0,2996 & 0,4353 & 0,6492 \\
\hline Efeito Mediaçâo & {$[0,2740 ; 0,4400]$} & {$[0,2481 ; 0,3900]$} & {$[0,3740 ; 0,5200]$} & {$[0,2233 ; 0,3800]$} & {$[0,3499 ; 0,5200]$} & {$[0,5315 ; 0,7600]$} \\
\hline Efeito Direto & $-0,9920$ & 7,7912 & $-3,1390$ & 3,5927 & 11,1788 & $-0,5673$ \\
\hline Efeito Direto & {$[-1,8990 ;-0,0500]$} & {$[6,9855 ; 8,6200]$} & {$[-3,8780 ;-2,3600]$} & {$[2,6281 ; 4,6000]$} & {$[10,3945 ; 11,9800]$} & {$[-1,2567 ; 0,1600]$} \\
\hline Efeito Toto & $-0,6390$ & 8,1080 & $-2,6930$ & 3,8923 & 11,6141 & 0,0819 \\
\hline Efeito lotal & {$[-1,548 ; 0,3100]$} & {$[7,3145 ; 8,9300]$} & {$[-3,4240 ;-1,9100]$} & {$[2,9302 ; 4,9000]$} & {$[10,8293 ; 12,4100]$} & {$[-0,6270 ; 0,7900]$} \\
\hline \multicolumn{7}{|c|}{ Filhas } \\
\hline Efeito Mediacão & 0,1912 & 0,1351 & 0,1528 & 0,1377 & 0,1253 & 0,2458 \\
\hline & {$[0,1155 ; 0,2700]$} & {$[0,0696 ; 0,2000]$} & {$[0,0802 ; 0,2200]$} & {$[0,0829 ; 0,1974]$} & {$[0,0636 ; 0,1944]$} & {$[0,1406 ; 0,3500]$} \\
\hline Efeito Direto & 0,7088 & 6,5140 & $-2,2929$ & 5,2486 & 10,2106 & $-0,2225$ \\
\hline & {$[-0,2437 ; 1,6900]$} & {$[5,7888 ; 7,2900]$} & {$[-3,0568 ;-1,5400]$} & {$[4,3297 ; 6,1809]$} & {$[9,5283 ; 10,9515]$} & {$[-0,9964 ; 0,6300]$} \\
\hline Efeito Total & 0,9000 & 6,6491 & $-2,1401$ & 5,3863 & 10,3359 & 0,0233 \\
\hline & {$[-0,0305 ; 1,8800]$} & {$[5,9280 ; 7,4300]$} & {$[-2,9003 ;-1,3900]$} & {$[4,4765 ; 6,3352]$} & {$[9,6521 ; 11,0811]$} & {$[-0,7626 ; 0,9000]$} \\
\hline
\end{tabular}


Tabela 4: Efeitos direto, indireto e total da escolaridade dos pais para a disciplina de Português (continuação)

\begin{tabular}{|c|c|c|c|c|c|c|}
\hline \multirow{3}{*}{ Efeitos } & \multicolumn{6}{|c|}{ Região Sul } \\
\hline & \multicolumn{3}{|c|}{ Tratamento: Educacão do Pai } & \multicolumn{3}{|c|}{ Tratamento: Educacão da Mãe } \\
\hline & Fundamental & Médio & Superior & Fundamental & Médio & Superior \\
\hline \multicolumn{7}{|c|}{ Filhos } \\
\hline Efeito Mediação & $\begin{array}{c}0,1814 \\
00981 \cdot 02721\end{array}$ & $\begin{array}{c}0,1405 \\
0775.02088\end{array}$ & $\begin{array}{c}0,3094 \\
0.073 .04\end{array}$ & $\begin{array}{c}0,1556 \\
0.0738 .02467]\end{array}$ & $\begin{array}{c}0,3521 \\
02234 \cdot 0\end{array}$ & $\begin{array}{c}0,6897 \\
0.5015 .08662]\end{array}$ \\
\hline & $-0,1062$ & 7,1256 & 1,0643 & 3,3200 & 8,5629 & 0,8022 \\
\hline Efeito Direto & {$[-1,4443 ; 1,1907]$} & {$[5,9286 ; 8,2858]$} & {$[-0,1469 ; 2,2383]$} & {$[1,8824 ; 4,7143]$} & {$[7,3698 ; 9,7192]$} & {$[-0,3896 ; 1,9574]$} \\
\hline Efeito Total & 0,0752 & 7,2662 & 1,3738 & 3,4761 & 8,9150 & 1,4920 \\
\hline & {$[-1,2578 ; 1,3615]$} & {$[6,0727 ; 8,4120]$} & {$[0,1768 ; 2,5324]$} & {$[2,0431 ; 4,8556]$} & {$[7,7350 ; 10,0567]$} & {$[0,3124 ; 2,6333]$} \\
\hline \multicolumn{7}{|c|}{ Filhas } \\
\hline Efeito Mediacão & 0,1998 & 0,1532 & 0,2433 & 0,1678 & 0,1991 & 0,3464 \\
\hline & {$[0,1091 ; 0,2982]$} & {$[0,0768 ; 0,2336]$} & {$[0,1055 ; 0,3731]$} & {$[0,0721 ; 0,2711]$} & {$[0,0910 ; 0,3054]$} & {$[0,1654 ; 0,5155]$} \\
\hline Efeito Direto & 2,5040 & 6,9716 & 0,1064 & 4,0956 & 9,1518 & 1,8315 \\
\hline Eretto Direto & {$[1,1427 ; 3,8235]$} & {$[5,8141 ; 8,0935]$} & {$[-1,1688 ; 1,3423]$} & {$[2,6582 ; 5,4888]$} & {$[7,9965 ; 10,2716]$} & {$[0,5786 ; 3,0457]$} \\
\hline Efeito Total & 2,7039 & 7,1248 & 0,3497 & 4,2635 & 9,3510 & 2,1779 \\
\hline Efeito lotal & {$[1,3482 ; 4,0136]$} & {$[5,9777 ; 8,2344]$} & {$[-0,9112 ; 1,5737]$} & {$[2,8393 ; 5,6447]$} & {$[8,2040 ; 10,4579]$} & {$[0,5786 ; 3,0457]$} \\
\hline
\end{tabular}

Fonte: Elaboração própria. 
Tabela 5: Efeitos direto, indireto e total da escolaridade dos pais para a disciplina de Matemática

\begin{tabular}{|c|c|c|c|c|c|c|}
\hline \multirow{3}{*}{ Efeitos } & \multicolumn{6}{|c|}{ Região Norte } \\
\hline & \multicolumn{3}{|c|}{$\begin{array}{c}\text { Tratamento: Educacão do Pai } \\
\end{array}$} & \multicolumn{3}{|c|}{ Tratamento: Educação da Mãe } \\
\hline & Fundamental & Médio & Superior & Fundamental & Médio & Superior \\
\hline \multicolumn{7}{|c|}{ Filhos } \\
\hline Efeito Mediação & $\begin{array}{c}0,4850 \\
{[0,2870 ; 0,6963]}\end{array}$ & $\begin{array}{c}0,8215 \\
{[0,5977 ; 1,0489]}\end{array}$ & $\begin{array}{c}0,9812 \\
07581 \cdot 12030]\end{array}$ & $\begin{array}{c}0,3871 \\
{[0,2004 \cdot 0,5897]}\end{array}$ & $\begin{array}{c}0,9784 \\
{[07277 \cdot 12312]}\end{array}$ & $\begin{array}{c}1,4576 \\
{[1,691 \cdot 17459]}\end{array}$ \\
\hline Efroito Direto & 0,3788 & 6,7727 & $-0,9873$ & 5,2252 & 10,6054 & {$[1,5289$} \\
\hline EIelto Direto & {$[-1,4150 ; 2,1175]$} & {$[5,0693 ; 8,4235]$} & {$[-2,5673 ; 0,5438]$} & {$[3,3442 ; 7,0483]$} & {$[8,9522 ; 12,2077]$} & {$[-1,0579 ; 2,0670]$} \\
\hline Efeito Total & 0,8639 & 7,5942 & $-0,0061$ & 5,6123 & 11,5839 & 1,9866 \\
\hline & {$[-0,9141 ; 2,6142]$} & {$[5,8971 ; 9,2437]$} & {$[-1,5804 ; 1,5290]$} & {$[3,7488 ; 7,4287]$} & {$[9,9477 ; 13,1856]$} & {$[0,3935 ; 3,5637]$} \\
\hline \multicolumn{7}{|c|}{ Filhas } \\
\hline Efeito Mediacão & 0,2570 & 0,4154 & 0,6754 & 0,3418 & 0,4579 & 0,9094 \\
\hline Efeito Mediaçao & {$[0,1165 ; 0,4139]$} & {$[0,2438 ; 0,5958]$} & {$[0,4427 ; 0,9021]$} & {$[0,1583 ; 0,5397]$} & {$[0,2891 ; 0,6340]$} & {$[0,6141 ; 1,1889]$} \\
\hline Efeito Direto & $-0,1198$ & 4,6116 & $-3,4439$ & 5,6612 & 9,8747 & 0,9669 \\
\hline Efeito Direto & {$[-1,9235 ; 1,6282]$} & {$[3,0361 ; 6,1386]$} & {$[-5,0427 ;-1,8944]$} & {$[3,7517 ; 7,5119]$} & {$[8,3390 ; 11,3631]$} & {$[-0,6665 ; 2,5501]$} \\
\hline Efeito Total & 0,1372 & 5,0270 & $-2,7685$ & 6,0031 & 10,3326 & 1,8763 \\
\hline Efelto lotal & {$[-1,6523 ; 1,8637]$} & {$[3,4647 ; 6,5330]$} & {$[-4,3524 ;-1,2327]$} & {$[4,1065 ; 7,8265]$} & {$[8,8064 ; 11,8057]$} & {$[0,2502 ; 3,4729]$} \\
\hline \multirow{3}{*}{ Efeitos } & \multicolumn{6}{|c|}{ Região Nordeste } \\
\hline & \multicolumn{3}{|c|}{ Tratamento: Educacão do Pai } & \multicolumn{3}{|c|}{ Tratamento: Educação da Mãe } \\
\hline & Fundamental & Médio & Superior & Fundamental & Médio & Superior \\
\hline \multicolumn{7}{|c|}{ Filhos } \\
\hline Efeito Mediacão & 0,3035 & 0,3281 & 0,3889 & 0,3267 & 0,4218 & 0,6785 \\
\hline Efeito Mediaçaoo & {$[0,1898 ; 0,4229]$} & {$[0,2097 ; 0,4511]$} & {$[0,2582 ; 0,5233]$} & {$[0,2075 ; 0,4508]$} & {$[0,2784 ; 0,5635]$} & {$[0,4765 ; 0,8691]$} \\
\hline Efeite Direto & $-0,1867$ & 5,5104 & $-2,4688$ & 4,4363 & 10,6221 & $-0,9605$ \\
\hline Efeito Direto & {$[-1,5215 ; 1,1069]$} & {$[4,1423 ; 6,8364]$} & {$[-3,8303 ;-1,1493]$} & {$[3,0638 ; 5,7667]$} & {$[9,3500 ; 11,8550]$} & {$[-2,3284 ; 0,3652]$} \\
\hline Efeito Total & 0,1168 & 5,8385 & $-2,0798$ & 4,7631 & 11,0439 & $-0,2820$ \\
\hline Efeito lotal & {$[-1,2036 ; 1,3909]$} & {$[4,4842 ; 7,1448]$} & {$[-3,4303 ;-0,7806]$} & {$[3,4048 ; 6,0725]$} & {$[9,7828 ; 12,2630]$} & {$[-1,6424 ; 1,0267]$} \\
\hline \multicolumn{7}{|c|}{ Filhas } \\
\hline Efeito Mediacão & 0,1576 & 0,1287 & 0,1949 & 0,1259 & 0,1665 & 0,2997 \\
\hline Efeıto Medıaçao & {$[0,0210 ; 0,2856]$} & {$[0,0185 ; 0,2330]$} & {$[0,0383 ; 0,3401]$} & {$[0,0161 ; 0,2342]$} & {$[0,0402 ; 0,2851]$} & {$[0,0892 ; 0,4964]$} \\
\hline Efeito Direto & 0,5292 & 6,0142 & $-4,5423$ & 3,4456 & 8,2599 & $-1,1245$ \\
\hline Efeito Direto & {$[-0,8281 ; 1,8447]$} & {$[4,7298 ; 7,2590]$} & {$[-5,9094 ;-3,2174]$} & {$[2,0671 ; 4,7817]$} & {$[7,0526 ; 9,4301]$} & {$[-2,5278 ; 0,2354]$} \\
\hline Efeito Total & 0,6868 & 6,1430 & $-4,3473$ & 3,5715 & 8,4265 & $-0,8248$ \\
\hline ETelto lotal & {$[-0,6541 ; 1,9883]$} & {$[4,8734 ; 7,3719]$} & {$[-5,6969 ;-3,0329]$} & {$[2,2103 ; 4,8903]$} & {$[7,2317 ; 9,5883]$} & {$[-2,2100 ; 0,5162]$} \\
\hline
\end{tabular}


Tabela 5: Efeitos direto, indireto e total da escolaridade dos pais para a disciplina de Matemática (continuação)

\begin{tabular}{|c|c|c|c|c|c|c|}
\hline \multirow{3}{*}{ Efeitos } & \multicolumn{6}{|c|}{ Região Centro-Oeste } \\
\hline & \multicolumn{3}{|c|}{ Tratamento: Educacão do Pai } & \multicolumn{3}{|c|}{ Tratamento: Educação da Mãe } \\
\hline & Fundamental & Médio & Superior & Fundamental & Médio & Superior \\
\hline \multicolumn{7}{|c|}{ Filhos } \\
\hline \multirow[t]{2}{*}{ Efeito Mediação } & $\begin{array}{c}0,3903 \\
{[01890 \cdot 06133]}\end{array}$ & $\begin{array}{c}0,5949 \\
{[04021 \cdot 07949]}\end{array}$ & $\begin{array}{c}0,9222 \\
006946 \cdot 1\end{array}$ & $\begin{array}{c}0,5252 \\
002711 \cdot 08051\end{array}$ & $\begin{array}{c}0,7660 \\
0.5439 \cdot 0.99271\end{array}$ & $\begin{array}{c}1,2624 \\
0886 \cdot 1,385]\end{array}$ \\
\hline & {$[0,10,4534$} & {$[0,0038$} & {$[0,0,0196$} & $\begin{array}{c}{[0,2711 ; 0,8005]} \\
4,837\end{array}$ & $\begin{array}{c}{[0,5439 ; 0,9927]} \\
10,6503\end{array}$ & $\begin{array}{c}{[0,9886 ; 1,5385]} \\
1,0614\end{array}$ \\
\hline Efeito Direto & {$[-1,4821 ; 2,3293]$} & {$[3,2694 ; 6,6847]$} & {$[-5,7211 ;-2,3705]$} & {$[2,7448 ; 6,8650]$} & {$[8,9319 ; 12,3157]$} & {$[-0,5981 ; 2,6699]$} \\
\hline \multirow{2}{*}{ Efeito Total } & 0,8437 & 5,5987 & $-3,0973$ & 5,3624 & 11,4163 & 2,3239 \\
\hline & {$[-1,0687 ; 2,7166]$} & {$[3,8775 ; 7,2921]$} & {$[-4,7894 ;-1,4528]$} & {$[3,2973 ; 7,4166]$} & {$[9,7062 ; 13,0781]$} & {$[0,6754 ; 3,9480]$} \\
\hline \multicolumn{7}{|c|}{ Filhas } \\
\hline \multirow{2}{*}{ Efeito Mediação } & 0,2986 & 0,3387 & 0,6891 & 0,2179 & 0,4121 & 0,8970 \\
\hline & {$[0,1451 ; 0,4701]$} & {$[0,1964 ; 0,4905]$} & {$[0,4606 ; 0,9205]$} & {$[0,0801 ; 0,3784]$} & {$[0,2389 ; 0,5948]$} & {$[0,6158 ; 1,1690]$} \\
\hline \multirow{2}{*}{ Efeito Direto } & 1,8395 & 3,7035 & $-3,2938$ & 4,6468 & 8,3171 & 1,4582 \\
\hline & {$[-0,0468 ; 3,6679]$} & {$[2,112 ; 5,2459]$} & {$[-4,9806 ;-1,6589]$} & {$[2,6472 ; 6,5849]$} & {$[6,7515 ; 9,8344]$} & {$[-0,2155 ; 3,0803]$} \\
\hline \multirow{2}{*}{ Efeito Total } & 2,1382 & 4,0423 & $-2,6046$ & 4,864 & 8,7291 & 2,3552 \\
\hline & {$[0,2647 ; 3,9436]$} & {$[2,4636 ; 5,5618]$} & {$[-4,2739 ;-0,9919]$} & {$[2,8750 ; 6,7856]$} & {$[7,1763 ; 10,2261]$} & {$[0,7005 ; 3,9817]$} \\
\hline \multirow{3}{*}{ Efeitos } & \multicolumn{6}{|c|}{ Região Sudeste } \\
\hline & \multicolumn{3}{|c|}{ Tratamento: Educacão do Pai } & \multicolumn{3}{|c|}{ Tratamento: Educação da Mãe } \\
\hline & Fundamental & Médio & Superior & Fundamental & Médio & Superior \\
\hline \multicolumn{7}{|c|}{ Filhos } \\
\hline \multirow{2}{*}{ Efeito Mediação } & 0,5350 & 0,5241 & 0,7330 & 0,4254 & 0,6738 & 1,0397 \\
\hline & {$[0,4380 ; 0,6400]$} & {$[0,4354 ; 0,6100]$} & {$[0,6460 ; 0,8300]$} & {$[0,3243 ; 0,5300]$} & {$[0,5772 ; 0,7700]$} & {$[0,9375 ; 1,1600]$} \\
\hline \multirow{2}{*}{ Efeito Direto } & $-0,2780$ & 6,8080 & $-3,1190$ & 3,6532 & 10,1391 & $-1,0295$ \\
\hline & {$[-1,2590 ; 0,6900]$} & {$[5,9848 ; 7,6200]$} & {$[-3,8570 ;-2,3600]$} & {$[2,6707 ; 4,6100]$} & {$[9,3227 ; 10,9800]$} & {$[-1,8230 ;-0,3000]$} \\
\hline \multirow{2}{*}{ Efeito Total } & 0,2580 & 7,3321 & $-2,3860$ & 4,0786 & 10,8128 & 0,0102 \\
\hline & {$[-0,7130 ; 1,2400]$} & {$[6,5147 ; 8,1200]$} & {$[-3,1190 ;-1,6100]$} & {$[3,0753 ; 5,0600]$} & {$[10,0006 ; 11,6600]$} & {$[-0,7667 ; 0,7400]$} \\
\hline \multicolumn{7}{|c|}{ Filhas } \\
\hline \multirow{2}{*}{ Efeito Mediação } & 0,3606 & 0,3732 & 0,4870 & 0,2487 & 0,3494 & 0,7360 \\
\hline & {$[0,2749 ; 0,4600]$} & {$[0,3045 ; 0,4500]$} & {$[0,4070 ; 0,5700]$} & {$[0,1800 ; 0,3200]$} & {$[0,2804 ; 0,4300]$} & {$[0,6150 ; 0,8500]$} \\
\hline \multirow{2}{*}{ Efeito Direto } & 0,6617 & 5,4392 & $-2,4870$ & 5,2198 & 8,9582 & $-0,1680$ \\
\hline & {$[-0,3165 ; 1,5500]$} & {$[4,7032 ; 6,2100]$} & {$[-3,2620 ;-1,7600]$} & {$[4,2783 ; 6,1600]$} & {$[8,2593 ; 9,7100]$} & {$[-0,9120 ; 0,6200]$} \\
\hline \multirow{2}{*}{ Efeito Total } & 1,0223 & 5,8124 & $-2,0000$ & 5,4684 & 9,3076 & 0,5680 \\
\hline & {$[0,0409 ; 1,9100]$} & {$[5,0760 ; 6,5900]$} & {$[-2,7940 ;-1,2800]$} & {$[4,5355 ; 6,4200]$} & {$[8,6072 ; 10,0600]$} & {$[-0,1720 ; 1,3500]$} \\
\hline
\end{tabular}


Tabela 5: Efeitos direto, indireto e total da escolaridade dos pais para a disciplina de Matemática (continuação)

\begin{tabular}{|c|c|c|c|c|c|c|}
\hline \multirow{3}{*}{ Efeitos } & \multicolumn{6}{|c|}{ Região Sul } \\
\hline & \multicolumn{3}{|c|}{$\begin{array}{c}\text { Tratamento: Educacão do Pai } \\
\end{array}$} & \multicolumn{3}{|c|}{ Tratamento: Educação da Mãe } \\
\hline & Fundamental & Médio & Superior & Fundamental & Médio & Superior \\
\hline \multicolumn{7}{|c|}{ Filhos } \\
\hline Efeito Mediação & $\begin{array}{c}0,3006 \\
{[0,1843 ; 0,4236]}\end{array}$ & $\begin{array}{c}0,2628 \\
{[0,1670 ; 0,3635]}\end{array}$ & $\begin{array}{c}0,5368 \\
{[0,4157 ; 0,6563]}\end{array}$ & $\begin{array}{c}0,2462 \\
{[0,1319 ; 0,3703]}\end{array}$ & $\begin{array}{c}0,6253 \\
{[0,4848 ; 0,7653]}\end{array}$ & $\begin{array}{c}1,1495 \\
{[0,9552 ; 1,3415]}\end{array}$ \\
\hline Efeito Direto & 0,2643 & 5,4229 & 0,1699 & 3,8321 & 6,8455 & 1,1154 \\
\hline Efeito Total & $\begin{array}{c}0,5650 \\
{[-0,7498 ; 1,8359]}\end{array}$ & $\begin{array}{c}5,6858 \\
{[4,5198 ; 6,8160]}\end{array}$ & $\begin{array}{c}0,7067 \\
{[-0,4742 ; 1,8507]}\end{array}$ & $\begin{array}{c}4,0784 \\
{[2,6715 ; 5,4432]}\end{array}$ & $\begin{array}{c}7,4709 \\
{[6,3065 ; 8,6013]}\end{array}$ & $\begin{array}{c}2,2649 \\
{[1,1068 ; 3,3994]}\end{array}$ \\
\hline \multicolumn{7}{|c|}{ Filhas } \\
\hline Efeito Mediação & $\begin{array}{c}0,2449 \\
{[0,1460 ; 0,3517]}\end{array}$ & $\begin{array}{c}0,2328 \\
{[0,1507 ; 0,3188]}\end{array}$ & $\begin{array}{c}0,4309 \\
{[0,2933 ; 0,5656]}\end{array}$ & $\begin{array}{c}0,2332 \\
{[0,1312 ; 0,3427]}\end{array}$ & $\begin{array}{c}0,3426 \\
{[0,2342 ; 0,4552]}\end{array}$ & $\begin{array}{c}0,5983 \\
{[0,4184 ; 0,7683]}\end{array}$ \\
\hline Efeito Direto & $\begin{array}{c}1,4124 \\
{[0.0946 \cdot 2,6895]}\end{array}$ & $\begin{array}{c}4,9485 \\
{[3.8275 \cdot 6.0350}\end{array}$ & $\begin{array}{c}0,1631 \\
{[-1,07847: 1,3665]}\end{array}$ & $\begin{array}{c}5,2499 \\
{[3,86115 \cdot 65959]}\end{array}$ & $\begin{array}{c}7,6394 \\
{[6,5168: 8,7275]}\end{array}$ & $\begin{array}{c}1,8296 \\
{[0.6095: 3.0122}\end{array}$ \\
\hline Efeito Total & 1,6574 & 5,1814 & 0,5941 & 5,4831 & 7,9821 & 2,4280 \\
\hline & {$[0,3473 ; 2,9238]$} & {$[4,0676 ; 6,2575]$} & {$[-0,6334 ; 1,7813]$} & {$[4,1022 ; 6,8161]$} & {$[6,8665 ; 9,0526]$} & {$[1,2160 ; 3,5938]$} \\
\hline
\end{tabular}

Fonte: Elaboração própria.

Nota: Os termos entre chave dizem respeito ao intervalo de confiança. 
se, assim, um diferencial menor para os tratados, ou até mesmo negativo.

Ressalta-se também que esses resultados negativos foram observados apenas para a escolaridade do pai, em que, por se tratar de filhos de pai com ensino superior e que estudam em escolas públicas, acredita-se que, embora este apresente Índice de Condição Socioeconômica superior aos outros pais que possuem apenas o fundamental ou o médio (ver Tabela 3), o pai não tem condição financeira suficiente para colocar os filhos em escolas particulares, embora com escolaridade mais elevada. Nesse caso, espera-se que, para assegurar essas melhores condições, o pai está mais propenso a trabalhos que, diante das exigências do mercado de trabalho, exigem mais horas trabalhadas, $o$ que pode reduzir o tempo de convivência destes para com os filhos, ao ponto de que o efeito desse pai sobre o desempenho do filho seja dado mais fortemente via condição socioeconômica, e ao isolar esse efeito da escolaridade do pai, esta passa a ser negativa. Entretanto, um efeito total negativo não implica, necessariamente, que pais mais escolarizados não possam intervir de forma eficaz na vida de seus filhos, pois estes podem influenciar positivamente o rendimento escolar dos filhos indiretamente, por meio de suas condições socioeconômicas, de modo a proporcioná-los maiores investimentos educacionais, além de um ambiente familiar mais adequado ao aprendizado de modo a compensar a restrição de tempo a qual estes estão sujeitos.

A fim de fazer comparações e dar suporte a esses resultados, buscou-se na literatura artigos que separem o efeito da educação da mãe e do pai sobre o desempenho dos filhos e que considerem outras variáveis no modelo, a fim de minimizar o viés e isolar esses efeitos, porém, não foi encontrado. de Araújo \& de Siqueira (2010) procuraram evidenciar quais atributos pessoais e escolares são determinantes no desempenho dos alunos em testes de proficiência de matemática para uma turma de $4^{a}$ série, mas consideraram apenas a escolaridade da mãe para representar a escolaridade dos pais. e Silva et al. (2017) avaliaram a influência da escolaridade dos pais (mãe e pai) e a renda familiar no desempenho dos alunos do ensino médio, por meio da análise de variância a partir dos microdados disponibilizados pelo INEP do ENEM realizado em 2013, entretanto, não estimaram os efeitos dessas variáveis levando em conta outras variáveis importantes na determinação do desempenho.

Levando-se em consideração a heterogeneidade dos efeitos entre pai e mãe, o efeito total da educação da mãe, para filhos e filhas, domina o efeito total da educação do pai, para todos os estratos de escolaridade, indicando que, a educação da mãe possui maior influência sobre os resultados escolares dos filhos do que o pai, para ambas as disciplinas, diferentemente do que é evidenciado por Marbuah (2016) e, Mendes \& Karruz (2012). Além disso, nas categorias de escolaridade média e superior, a educação da mãe possui maior influência tanto direta quanto indireta sobre os resultados acadêmicos de filhos e filhas, quando comparada aos mesmos estratos educacionais do pai, indicando que a mãe possui maior influência no resultado dos filhos do que o pai, tanto direta quanto indiretamente.

Uma maior importância da educação da mãe sobre o rendimento escolar dos filhos pode ser explicada pela maior convivência desta com a criança, de modo que, mães mais escolarizadas podem otimizar o tempo gasto com os filhos, tornando mais eficiente o seu envolvimento para com estes, ao ponto de

vel superior torna-se negativa, comprovando que os sinais permanecem robustos mesmo após mudança de método. 
auxiliá-los na realização de tarefas extraescolares. Na categoria mais baixa de escolaridade, em média, o pai possui uma influência indireta marginalmente maior do que a da mãe, com maior diferencial registrado nas regiões Norte $(20 \%)$ e Sudeste $(38,85 \%)$, para filhos e filhas, respectivamente, em Língua Portuguesa e, em Matemática a Região Sudeste com 25,76\% para homens e $45 \%$ para mulheres.

Ao comparar o efeito total causal de cada tratamento entre gênero, verificase que, na Região Norte, para as duas disciplinas, o nível de educação do pai exerce maior influência sobre o rendimento escolar dos filhos do que para as filhas, para todos os estratos de escolaridade, não havendo um padrão para as demais regiões. Ressalta-se também, para a mesma região, que o diferencial de efeitos da educação do pai entre filhos e filhas é maior no estrato de ensino superior, com diferença de 2,7 pontos, em Português, e 2,8 pontos em Matemática, a favor de alunos do sexo masculino. Observa-se, também, um padrão para o efeito total da educação da mãe nas regiões Nordeste e Sul. No Nordeste, a educação da mãe possui maior influência sobre os resultados dos filhos, com maior diferencial de efeito no estrato de ensino médio completo, com magnitude de 2,2 e 2,6 pontos em Português e Matemática, respectivamente, a favor dos filhos. Já para a Região Sul esse efeito é maior para as filhas, com maior diferença de efeitos entre gênero na categoria de ensino fundamental, com 0,79 e 1,4 pontos a mais que os homens, em Português e Matemática, respectivamente. Ressalta-se também que, não foi verificado um mesmo padrão, para todos os estratos de escolaridade, nas demais regiões.

Ao comparar os efeitos totais estimados entre regiões, os resultados para as duas disciplinas evidenciam que, na Região Sul filhos e filhas reagem mais ao efeito da educação do pai do que nas demais regiões, para o estrato mais alto de educação. Em relação aos níveis de educação, fundamental e médio, a escolaridade do pai possui influência mais efetiva sobre a Região Norte, para os filhos. Já para as filhas, tal efeito é maior para o Centro-Oeste, para o estrato inferior da educação do pai, e para a categoria de ensino superior encontra-se a Região Nordeste, a qual se mostrou mais sensível à educação do pai para esse nível de escolaridade, tanto em Português quanto em Matemática. Em relação à educação da mãe, alunos pertencentes à Região Norte reagem mais ao efeito total da escolaridade da mãe com ensino fundamental ou médio completo, excetuando-se os filhos, para o estrato de ensino médio, na disciplina de Português, sendo que, o Nordeste registra maior influência total com magnitude de 12,8 pontos, aproximadamente. Para a categoria de educação mais elevada (ensino superior), os maiores efeitos totais para os filhos são registrados pela Região Centro-Oeste com magnitude de 2,5 e 2,3 pontos, aproximadamente, a favor dos tratados, para as proficiências de Português e Matemática, respectivamente. Já para as filhas, o impacto total da educação da mãe com ensino superior é verificado na Região Sul do país, com importância de 2,2 e 2,4 pontos em Português e Matemática, respectivamente.

Particionando o efeito total causal pode-se verificar uma heterogeneidade dos efeitos, tanto direto quanto indireto, entre homens e mulheres e, também, entre regiões. A influência indireta da escolaridade tanto do pai quanto da mãe via mediação das condições socioeconômicas, em média, é maior para os filhos do que para as filhas, para todos os níveis de educação dos pais considerados neste estudo, indicando que, o efeito mediação via condição socioeconômica da família perde força quando o filho é do sexo feminino, para ambas as regiões do Brasil. Ressalta-se também que, o maior diferencial de efeitos 
entre gênero é verificado na Região Nordeste, em todos os estratos de educação, com maior heterogeneidade nos níveis de escolaridade, médio $(466,1 \%)$ e superior $(312,1 \%)$ em Português e, em Matemática, médio (154,9\%) e fundamental $(159,5 \%)$, para pai e mãe, respectivamente.

Em relação às diferenças inter-regionais do efeito de mediação causal, os resultados para Português evidenciam que, na Região Norte, os alunos reagem mais ao efeito da educação dos pais via condição socioeconômica do que alunos das demais regiões, para todas as categorias de educação dos pais, excetuando-se a primeira, para a educação da mãe, para a qual o maior efeito indireto é registrado pelo Centro-Oeste ( 0,5 pontos) para estudantes do sexo masculino. O mesmo é verificado para Matemática, exceto para o estrato inferior de escolaridade do pai, sendo que o Sudeste registra os maiores efeitos médios de mediação causal com magnitude de 0,54 e 0,36 pontos, para homens e mulheres, respectivamente, e para filhas de pai com ensino superior e filhos de mãe com ensino fundamental pertencentes à Região Centro-Oeste. No que diz respeito ao efeito direto, a maior influência positiva do mesmo, é verificado na Região Norte para filhos de pai com ensino fundamental e médio completo, em Português, e filhas de mãe com esse mesmo nível de escolaridade, para ambas as disciplinas. Os resultados do estrato mais elevado de educação dos pais revelam que a Região Sul reage mais ao efeito direto da educação do pai do que as demais regiões do país. Resultado semelhante é verificado para o efeito direto da educação da mãe, para o mesmo nível de escolaridade, com exceção dos filhos, sendo que tal efeito é maior no CentroOeste para a disciplina de Português, com magnitude de 1,4 pontos a favor dos indivíduos tratados.

\section{Considerações Finais}

Este estudo visa mensurar os efeitos do nível de escolaridade dos pais sobre o desempenho escolar de alunos do $5^{\circ}$ ano do ensino fundamental da rede pública de ensino, levando-se em consideração a heterogeneidade de tais efeitos entre gêneros e regiões, da área urbana do Brasil. O mesmo fez uso de informações extraídas do SAEB, Censo Escolar e da Plataforma de Indicadores Sociais disponibilizadas pelo INEP, para o ano de 2015.

Estudos referentes ao desempenho escolar evidenciam que maiores níveis educacionais dos pais estão associados a melhores resultados escolares de seus filhos, tanto a nível nacional (Melo \& Arakawa 2012, Mendes \& Karruz 2012), quanto a nível internacional (Glick \& Sahn 2000, Chen 2009, Jerrim \& Micklewright 2011). No entanto, uma determinada parcela dessa contribuição da educação dos pais se dá de forma indireta via condição socioeconômica da família, até então, não levada em consideração pela literatura. Desse modo, este estudo pretende contribuir com a literatura ao estimar as direções causais da educação dos pais sobre o rendimento escolar dos filhos, além de decompor tal efeito em duas parcelas, efeito direto e indireto, sendo que, neste último, a escolaridade dos pais afeta indiretamente o desempenho dos filhos por meio do nível socioeconômico da família, a qual se encontra na via de causalidade entre o nível de instrução dos pais e o desempenho escolar dos alunos.

Visando atingir o objetivo proposto por este trabalho, utilizou-se o método de efeito de mediação causal, o qual permite capturar a parcela do efeito de uma variável de tratamento sobre a variável de resultado que pode ser expli- 
cado por seu efeito na variável mediadora, permitindo, assim, particionar o efeito médio total da escolaridade dos pais nos efeitos, direto e indireto (mediação).

A partir dos resultados encontrados, verificou-se que, o efeito médio de mediação causal ganha força à medida que a educação dos pais aumenta, indicando que, pais mais escolarizados possuem, em média, melhores condições socioeconômicas, potencializando-se, assim, o efeito indireto da educação dos mesmos sobre o rendimento escolar dos filhos via condição socioeconômica da família. Ademais, no extremo superior de educação (superior completo), em média, há uma predominância do efeito indireto em detrimento ao efeito direto, sobre o rendimento escolar dos filhos, sugerindo que, pais com ensino superior completo possuem maior influência via condição socioeconômica do que de forma direta, indicando que, o efeito da educação dos pais para o extremo superior da distribuição de escolaridade destes, pode ser superestimado ao desconsiderar o efeito indireto associado ao nível socioeconômico da família, até então, não levado em consideração pela literatura.

As estimativas também mostram que o impacto total da educação da mãe domina o efeito total da educação do pai em todos os níveis de escolaridade. Além disso, nas categorias de escolaridade média e superior, a educação da mãe possui maior influência tanto direta quanto indireta sobre os resultados acadêmicos de filhos e filhas, quando comparada aos mesmos estratos educacionais do pai.

Torna-se importante destacar também que os resultados aqui encontrados apontam para diferenças nos efeitos causais entre gêneros e regiões, indicando que, filhos e filhas, além das macrorregiões brasileiras, reagem de forma diferenciada aos efeitos da educação dos pais. Na Região Norte, o nível de instrução do pai exerce maior influência sobre o rendimento escolar dos filhos quando comparado às filhas, em todos os estratos de educação. Em relação à educação da mãe, esta possui maior influência sobre os resultados dos filhos, na Região Nordeste, e maior efeito sobre as filhas pertencentes à Região Sul do país.

Ao decompor o efeito total verificou-se que, a influência indireta da escolaridade dos pais via mediação das condições socioeconômicas, em média, é maior para os filhos do que para as filhas, em todos os estratos de escolaridade dos pais, evidenciando que, o efeito médio de mediação causal perde força quando o filho é do sexo feminino, para ambas as regiões do país.

Diante do exposto, os resultados sugerem que pais mais escolarizados transmitem para seus filhos uma determinada parcela de vantagens educacionais por meio do nível socioeconômico familiar, o qual é afetado pela educação dos mesmos devido aos retornos privados do capital humano. Este estudo também procurou contribuir com a literatura ao fornecer indícios que, parte da disparidade de desempenho entre meninos e meninas e entre regiões estão associadas não apenas às desigualdades na distribuição de características relacionadas a esses grupos, mas, também, as formas pelas quais estes reagem a diferentes fatores, em especial, a educação dos pais.

\section{Referências Bibliográficas}

Albernaz, A., Ferreira, F. H. G. \& Franco, C. (2002), 'Qualidade e equidade no Ensino Fundamental brasileiro', Pesquisa e Planejamento Econômico - IPEA 
$32,453-76$.

Araújo, E. S. d. P. \& Almeida, A. T. C. d. (2013), 'Avaliação dos resultados educacionais dos alunos das escolas municipais de João Pessoa - PB', Gestão E Aprendizagem 2(2), 46-63.

Associação Brasileira de Empresas de Pesquisa (2014), 'Critério de classificação econômica Brasil'.

Barbosa, M. E. F. \& Fernandes, C. (2001), 'A escola brasileira faz diferença? Uma investigação dos efeitos da escola na proficiência em Matemática dos alunos da $4^{\mathrm{a}}$ série', Promoção, Ciclos e Avaliação Educacional, Porto Alegre, ArtMed pp. 155-172.

Barros, R. P. \& Lam, D. (1993), 'Desigualdade de renda, desigualdade em educação e escolaridade das crianças no Brasil', Pesquisa e Planejamento Econômico 23(2).

Becker, G. S. \& Chiswick, B. R. (1966), 'Education and the distribution of earnings', The American Economic Review (56), 358-369.

Chen, Q. (2009), 'Family background, ability and student achievement in rural China - identifying the effects of unobservable ability using faminegenerated instruments', Gansu Survey of Children and Families.

Coleman, J. S. (1966), 'Equality of educational opportunity', Washington, U.S. Government Printing Office.

de Araújo, F. R. A. \& de Siqueira, L. B. O. (2010), 'Determinantes do desempenho escolar dos alunos da $4^{\text {a }}$ série do Ensino Fundamental no Brasil', Revista Economia e Desenvolvimento 9(2).

de Serf'02, M. (2002), 'The effects of family, social and background factors on children's educational attainment', Honors Projects.

e Silva, A. C. L., de Oliveira Mota, R., Lima, J. C. F., Queiroz, F. C. B. P. \& Noronha, S. L. (2017), 'A influência da escolaridade dos pais e da renda familiar no desempenho dos candidatos do ENEM', XXXVII Encontro Nacional de Engenharia de Produção.

Felício, F. \& Fernandes, R. (2005), 'O efeito da qualidade da escola sobre o desempenho escolar: uma avaliação do Ensino Fundamental do Estado de São Paulo', Encontro Nacional da ANPEC, Anais do XXXIII Encontro Nacional da ANPEC.

Glick, P. \& Sahn, D. E. (2000), 'Schooling of girls and boys in a West African country: the effects of parental education, income, and household structure', Economics of Education Review 19(1), 63-87.

Gonçalves, M. E., Rios-Neto, E. L. \& César, C. C. (2008), 'Evasão no Ensino Fundamental brasileiro: identificação e análise dos principais determinantes', XVI Encontro Nacional de Estudos Populacionais, Caxambu.

Hanushek, E. A. \& Woessmann, L. (2010), 'Education and economic growth', Economics of Education pp. 60-67. 
Imai, K., Tingley, D. \& Keele, L. (2010), 'A general approach to causal mediation analysis', Psychological Methods 15(4), 309-334.

Instituto Nacional de Estudos e Pesquisas Educacionais Anísio Teixeira (2015a), 'Indicador de adequação da formação do docente da educação básica'.

Instituto Nacional de Estudos e Pesquisas Educacionais Anísio Teixeira (2015b), 'Microdados do SAEB (ANEB/Prova Brasil)'.

Jerrim, J. \& Micklewright, J. (2011), 'Children's cognitive ability and parents' education: distinguishing the impact of mothers and fathers', Persistence, Privilege and Parenting: The Comparative Study of Intergenerational Mobility, Russell Sage Foundation, New York, NY.

Levacic, R., Jenkins, A., Vignoles, A., Steele, F. \& Allen, R. (2005), Estimating the relationship between school resources and pupil attainment at Key Stage 3, Department for Education and Skills/Institute of Education, University of London, Londres.

Lochner, L. \& Moretti, E. (2004), 'The effect of education on crime: evidence from prison inmates, arrests, and self-reports', American Economic Review 94(1), 155-189.

Marbuah, D. A.-A. (2016), 'Influence of parental income and educational attainment on children's years of schooling: case of Ghana', Master's thesis in Sociology of Education.

Medeiros, M. \& de Oliveira, L. F. B. (2013), 'Potencial de convergência regional em educação no Brasil', Instituto de Pesquisa Econômica Aplicada (IPEA). Texto para Discussão.

Melo, L. M. C. \& Arakawa, V. H. (2012), 'Existe desigualdade regional na relação entre background familiar e desempenho escolar dos filhos? Evidências para as grandes regiões do Brasil', XVIII Encontro Nacional de Estudos Populacionais, ABEP. São Paulo.

Mendes, B. D. \& Karruz, A. P. (2012), 'Background familiar, desigualdade regional e o desempenho no Exame Nacional do Ensino Médio (ENEM)', Belo Horizonte, Universidade Federal de Minas Gerais (UFMG) pp. 1-25.

Menezes Filho, N. A. (2012), Os determinantes do desempenho escolar do Brasil, 1 edn, Saraiva, São Paulo.

Nieto, S. \& Ramos, R. (2013), 'Decomposition of differences in PISA results in middle income countries', Background paper prepared for the education for all global monitoring report 2013/4, Teaching and learning: achieving quality for all.

Palermo, G. A., Silva, D. B. N., Novellino, M. S. F. et al. (2014), 'Fatores associados ao desempenho escolar: uma análise da proficiência em Matemática dos alunos do $5^{\circ}$ ano do Ensino Fundamental da rede municipal do Rio de Janeiro', Revista Brasileira de Estudos de População 31(2), 367-394. 
Peraita, C. \& Sánchez, M. (1998), 'The effect of family background on children's level of schooling attainment in Spain', Applied Economics 30(10), 1327-1334.

Shirasu, M. R. \& Arraes, R. d. A. (2015), 'Determinantes da Evasão e Repetência Escolar no Ensino Médio do Ceará', Rev. Econ. NE, Fortaleza 46, 117-136.

Soares, J. F. (2004), 'O efeito da escola no desempenho cognitivo de seus alunos', REICE - Revista Electrónica Iberoamericana sobre Calidad, Eficacia y Cambio en Educación 2(2).

Soares, S. \& Sátyro, N. (2008), 'O impacto de infra-estrutura escolar na taxa de distorção idade-série das escolas brasileiras de ensino fundamental: 1998 a 2005'.

Souza, M. I. A., Taques, F. H., de Oliveira, J. d. C. \& Alencar, D. A. (2013), 'Relação entre a desigualdade e educação no Brasil: uma estimativa de dados em painel (1995-2009)', Textos de Economia 16(2), 111-142.

Steele, F., Vignoles, A. \& Jenkins, A. (2007), 'The effect of school resources on pupil attainment: a multilevel simultaneous equation modelling approach', Journal of the Royal Statistical Society, Series A (Statistics in Society) 170(3), 801-824.

Vieira, M. A. \& Tenório, R. M. (2014), 'Impacto da escolaridade dos pais e nível socioeconômico familiar nos resultados de testes cognitivos', IV Congresso Ibero, Americano de Política e Administração da Educação, VII Congresso Luso Brasileiro de Política e Administração da Educação, Porto, Portugal. 


\section{Apêndice $A$}

\section{Análise de Componentes Principais (PCA)}

Com o intuito de agregar as informações contidas nas variáveis descritas na Tabela 2 em uma só variável, Índice de Condição Socioeconômica dos Alunos, utilizou-se o método estatístico de Análise dos Componentes Principais (PCA), o qual tem por objetivo reduzir um conjunto de variáveis em uma única que possa explicar as variabilidades desse conjunto, por meio da combinação linear não correlacionada de comprimento unitário do conjunto de variáveis que contêm a maior parte da variação, particionando, assim, as informações contidas nas variáveis em componentes ortogonais, sendo que o primeiro componente possui a maior variabilidade e, consequentemente, contendo mais informações, dentre todos os demais componentes posteriores.

Considere uma matriz $C_{n \times n}$ de correlação ou de covariância do conjunto de variáveis, utilizadas para a criação do PCA, a serem analisadas. A decomposição da matriz $C$ é dada por

$$
C=V \wedge V^{\prime}=\sum_{i=1}^{n} \lambda_{i} V_{i} V_{i}^{\prime}
$$

em que os $\lambda_{i}$ é o $i$-ésimo autovalor associado ao $i$-ésimo autovetor $V_{i}$ associados à matriz $C$, na qual os autovetores são ortogonais. Os Autoval medem as variâncias dos componentes principais, e, consequentemente, tem-se que $\lambda_{1} \geq \lambda_{2} \geq \ldots \lambda_{n} \geq 0$, pois como dito anteriormente os componentes principais predecessores possuem maior variância em comparação aos seus sucessores. Ressalta-se também que a matriz $\wedge$ corresponde à matriz diagonal na qual nas entradas da diagonal principal estão os Autoval e, diante disso, $\operatorname{Tr}(C)=\sum_{i=1}^{n} \lambda_{i}=$ variância total do conjunto de variáveis. Já os autovetores são os próprios componentes da matriz $C$.

Os resultados da Análise de Componentes Principais (PCA), gerados para cada tratamento considerado nesse estudo, estão explicitados na Tabela A.1 a qual apresenta os Autoval da matriz de correlação, do maior para o menor, associados a cada componente, além da proporção de informações contidas em cada componente principal. Além do mais, a mesma também explicita os autovetores de cada variável levada em consideração para a criação do índice, associados às suas respectivas componentes. Os autovetores correspondentes são os componentes principais os quais possuem Comprimento 1, pois, a soma dos quadrados dos coeficientes das variáveis associados a cada componente, em particular, é unitário, por exemplo, da primeira coluna (Componente 1) na parte da tabela que descreve os autovetores, tem-se que $(0,3302)^{2}+(0,2453)^{2}+$ $(0,1401)^{2}+(0,3928)^{2}+(0,3825)^{2}+(0,4427)^{2}+(0,3043)^{2}+(0,1465)^{2}=1$.

O conjunto de informações aqui considerado para o cálculo das componentes é composto por nove variáveis, as quais são descritas na Tabela 2. Foram geradas, ao todo, nove componentes, sendo que a primeira corresponde a cerca de $21 \%$ a $22 \%$ da variância total, enquanto a última, contém cerca de $7 \%$ a $8 \%$ das informações contidas no conjunto de variáveis. 
Tabela A.1: Componentes principais - autovalores

\begin{tabular}{|c|c|c|c|c|c|c|c|c|}
\hline \multirow{2}{*}{ Componentes } & Autovalores & Diferença & Proporção & Cumulativo & Autovalores & Diferença & Proporção & Cumulativo \\
\hline & \multicolumn{4}{|c|}{ Tratamento Nível 1: Educação da Mãe } & \multicolumn{4}{|c|}{ Tratamento Nível 1: Educação do Pai } \\
\hline Componente1 & 1,9349 & 0,9009 & 0,2150 & 0,2150 & 1,9415 & 0,9047 & 0,2157 & 0,2157 \\
\hline Componente2 & 1,0340 & 0,0303 & 0,1149 & 0,3299 & 1,0368 & 0,0300 & 0,1152 & 0,3309 \\
\hline Componente3 & 1,0037 & 0,0387 & 0,1115 & 0,4414 & 1,0068 & 0,0395 & 0,1119 & 0,4428 \\
\hline Componente 4 & 0,9650 & 0,0380 & 0,1072 & 0,5486 & 0,9673 & 0,0446 & 0,1075 & 0,5502 \\
\hline Componente5 & 0,9269 & 0,0575 & 0,1030 & 0,6516 & 0,9227 & 0,0534 & 0,1025 & 0,6528 \\
\hline Componente6 & 0,8694 & 0,0830 & 0,0966 & 0,7482 & 0,8693 & 0,0829 & 0,0966 & 0,7494 \\
\hline Componente7 & 0,7864 & 0,0299 & 0,0874 & 0,8356 & 0,7864 & 0,0332 & 0,0874 & 0,8367 \\
\hline Componente8 & 0,7566 & 0,0335 & 0,0841 & 0,9197 & 0,7532 & 0,0369 & 0,0837 & 0,9204 \\
\hline Componente9 & 0,7231 & - & 0,0803 & 1 & 0,7162 & - & 0,0796 & 1 \\
\hline Componentes & \multicolumn{4}{|c|}{ Tratamento Nível 2: Educação da Mãe } & \multicolumn{4}{|c|}{ Tratamento Nível 2: Educação do Pai } \\
\hline Componente1 & 1,9422 & 0,9038 & 0,2158 & 0,2158 & 1,9516 & 0,9111 & 0,2168 & 0,2168 \\
\hline Componente2 & 1,0383 & 0,0252 & 0,1154 & 0,3312 & 1,0405 & 0,0279 & 0,1156 & 0,3324 \\
\hline Componente3 & 1,0131 & 0,0399 & 0,1126 & 0,4437 & 1,0125 & 0,0395 & 0,1125 & 0,4449 \\
\hline Componente4 & 0,9733 & 0,0544 & 0,1081 & 0,5519 & 0,9730 & 0,0586 & 0,1081 & 0,5531 \\
\hline Componente 5 & 0,9189 & 0,0524 & 0,1021 & 0,6540 & 0,9144 & 0,0484 & 0,1016 & 0,6547 \\
\hline Componente6 & 0,8665 & 0,0790 & 0,0963 & 0,7503 & 0,8661 & 0,0785 & 0,0962 & 0,7509 \\
\hline Componente7 & 0,7875 & 0,0382 & 0,0875 & 0,8378 & 0,7876 & 0,0389 & 0,0875 & 0,8384 \\
\hline Componente8 & 0,7493 & 0,0384 & 0,0833 & 0,9210 & 0,7487 & 0,0431 & 0,0832 & 0,9216 \\
\hline Componente9 & 0,7109 & & 0,0790 & 1 & 0,7057 & & 0,0784 & 1 \\
\hline Componentes & \multicolumn{4}{|c|}{ Tratamento Nível 3: Educação da Mãe } & \multicolumn{4}{|c|}{ Tratamento Nível 3: Educação do Pai } \\
\hline Componente1 & 2,0135 & 0,9633 & 0,2237 & 0,2237 & 2,0135 & 0,9633 & 0,2237 & 0,2237 \\
\hline Componente 2 & 1,0503 & 0,0329 & 0,1167 & 0,3404 & 1,0503 & 0,0329 & 0,1167 & 0,3404 \\
\hline Componente3 & 1,0174 & 0,0447 & 0,1130 & 0,4535 & 1,0174 & 0,0447 & 0,1130 & 0,4535 \\
\hline Componente 4 & 0,9726 & 0,0826 & 0,1081 & 0,5615 & 0,9726 & 0,0826 & 0,1081 & 0,5615 \\
\hline Componente5 & 0,8901 & 0,0400 & 0,0989 & 0,6604 & 0,8901 & 0,0400 & 0,0989 & 0,6604 \\
\hline Componente6 & 0,8501 & 0,0631 & 0,0945 & 0,7549 & 0,8501 & 0,0631 & 0,0945 & 0,7549 \\
\hline Componente7 & 0,7869 & 0,0558 & 0,0874 & 0,8423 & 0,7869 & 0,0558 & 0,0874 & 0,8423 \\
\hline Componente 8 & 0,7311 & 0,0431 & 0,0812 & 0,9236 & 0,7311 & 0,0431 & 0,0812 & 0,9236 \\
\hline Componente 9 & 0,6880 & - & 0,0764 & 1 & 0,6880 & - & 0,0764 & 1 \\
\hline
\end{tabular}


Tabela A.1: Componentes principais - autovetores (continuação)

\begin{tabular}{|c|c|c|c|c|c|c|c|c|c|}
\hline Variável & Comp1 & Comp2 & Comp3 & Comp4 & Comp5 & Comp6 & Comp7 & Comp8 & Comp9 \\
\hline \multicolumn{10}{|c|}{ Tratamento Nível 1: Educação da Mãe } \\
\hline $\mathrm{Tv}$ & 0,4478 & 0,1146 & $-0,2034$ & $-0,0626$ & $-0,1405$ & $-0,0934$ & $-0,2982$ & $-0,4363$ & $-0,6583$ \\
\hline Radio & 0,3302 & 0,2262 & $-0,4724$ & $-0,0524$ & $-0,0856$ & $-0,6273$ & 0,1492 & 0,3904 & 0,1959 \\
\hline Dvd & 0,2453 & 0,5822 & $-0,3125$ & 0,0946 & 0,2784 & 0,6011 & $-0,0719$ & 0,0329 & 0,2218 \\
\hline Geladeira & 0,1401 & 0,4641 & 0,5878 & 0,5568 & 0,0329 & $-0,3024$ & 0,0529 & $-0,1152$ & 0,0298 \\
\hline Freezer & 0,3928 & $-0,0818$ & 0,2257 & $-0,2766$ & 0,2951 & 0,115 & 0,7474 & 0,0293 & $-0,2278$ \\
\hline Maq_roupa & 0,3825 & $-0,1809$ & 0,3660 & $-0,1725$ & 0,2845 & 0,0243 & $-0,5431$ & 0,5285 & $-0,0364$ \\
\hline Carro & 0,4427 & $-0,2706$ & 0,0804 & $-0,1302$ & $-0,0552$ & $-0,0515$ & $-0,0872$ & $-0,5242$ & 0,6475 \\
\hline Banheiro & 0,3043 & $-0,1286$ & 0,0736 & 0,2418 & $-0,7710$ & 0,3579 & 0,1302 & 0,296 & $-0,0025$ \\
\hline Empregada & 0,1465 & $-0,5022$ & $-0,3090$ & 0,7019 & 0,3590 & 0,0222 & 0,0523 & 0,0195 & $-0,0754$ \\
\hline \multicolumn{10}{|c|}{ Tratamento Nível 2: Educação da Mãe } \\
\hline TV & 0,4571 & 0,1038 & $-0,1801$ & $-0,0529$ & $-0,1745$ & $-0,0565$ & $-0,2243$ & $-0,4286$ & $-0,6909$ \\
\hline Rádio & 0,3218 & 0,3035 & $-0,4284$ & $-0,0775$ & $-0,1087$ & $-0,6522$ & 0,1099 & 0,3527 & 0,2025 \\
\hline DVD & 0,2317 & 0,6173 & $-0,2658$ & 0,0068 & 0,3441 & 0,5767 & $-0,0785$ & 0,0227 & 0,1921 \\
\hline Geladeira & 0,1127 & 0,4122 & 0,5302 & 0,6892 & $-0,0582$ & $-0,2107$ & 0,0569 & $-0,0993$ & 0,0206 \\
\hline Freezer & 0,3811 & $-0,0536$ & 0,3141 & $-0,2833$ & 0,2611 & 0,0525 & 0,756 & 0,0549 & $-0,1658$ \\
\hline Lavadora & 0,3757 & $-0,1457$ & 0,4219 & $-0,1668$ & 0,2506 & $-0,0276$ & $-0,5691$ & 0,4916 & $-0,0518$ \\
\hline Carro & 0,4514 & $-0,2508$ & 0,0813 & $-0,0920$ & $-0,0732$ & $-0,0365$ & $-0,1064$ & $-0,5409$ & 0,6385 \\
\hline Banheiro & 0,3233 & $-0,2218$ & $-0,0996$ & 0,2771 & $-0,6394$ & 0,4331 & 0,1368 & 0,3786 & 0,0320 \\
\hline Empregada & 0,1627 & $-0,4582$ & $-0,3730$ & 0,5682 & 0,5392 & $-0,0446$ & 0,0520 & 0,0278 & $-0,0742$ \\
\hline \multicolumn{10}{|c|}{ Tratamento Nível 3: Educação da Mãe } \\
\hline TV & 0,4562 & 0,0447 & 0,1854 & $-0,0291$ & $-0,2164$ & $-0,0724$ & $-0,1555$ & $-0,5071$ & $-0,6490$ \\
\hline Rádio & 0,3095 & 0,2391 & 0,4745 & $-0,0862$ & $-0,3605$ & 0,5944 & 0,0419 & 0,3176 & 0,1692 \\
\hline DVD & 0,2168 & 0,5438 & 0,4130 & $-0,0285$ & 0,5436 & $-0,3991$ & $-0,0730$ & 0,0465 & 0,1535 \\
\hline Geladeira & 0,0937 & 0,4748 & $-0,3547$ & 0,7774 & $-0,1071$ & 0,1172 & 0,0705 & $-0,0703$ & 0,0230 \\
\hline Freezer & 0,3606 & 0,1141 & $-0,3657$ & $-0,3174$ & 0,1798 & 0,0574 & 0,7431 & 0,1038 & $-0,1544$ \\
\hline Lavadora & 0,3550 & 0,0561 & $-0,4905$ & $-0,2025$ & 0,1602 & 0,1186 & $-0,6290$ & 0,3814 & $-0,0915$ \\
\hline Carro & 0,4586 & $-0,1961$ & $-0,1379$ & $-0,0626$ & $-0,0763$ & $-0,0398$ & $-0,0534$ & $-0,4856$ & 0,6944 \\
\hline Banheiro & 0,3508 & $-0,3211$ & 0,1041 & 0,2763 & $-0,3310$ & $-0,5693$ & 0,1049 & 0,4919 & 0,0063 \\
\hline Empregada & 0,2253 & $-0,5118$ & 0,1998 & 0,4057 & 0,5855 & 0,3542 & 0,0452 & 0,0306 & $-0,1075$ \\
\hline
\end{tabular}


Tabela A.1: Componentes principais - autovetores (continuação)

\begin{tabular}{|c|c|c|c|c|c|c|c|c|c|}
\hline Variável & Comp1 & Comp2 & Comp3 & Comp4 & Comp5 & Comp6 & Comp7 & Comp8 & Comp9 \\
\hline \multicolumn{10}{|c|}{ Tratamento Nível 1: Educação do Pai } \\
\hline TV & 0,4503 & 0,1300 & $-0,1931$ & $-0,0472$ & $-0,1559$ & $-0,0751$ & $-0,2576$ & $-0,4664$ & $-0,6535$ \\
\hline Rádio & 0,3242 & 0,2983 & $-0,4337$ & $-0,0679$ & $-0,0925$ & $-0,6387$ & 0,1229 & 0,3809 & 0,1909 \\
\hline DVD & 0,2414 & 0,5981 & $-0,2601$ & 0,0755 & 0,3208 & 0,5994 & $-0,0655$ & 0,0445 & 0,2054 \\
\hline Geladeira & 0,1349 & 0,4024 & 0,6142 & 0,5904 & 0,0288 & $-0,2747$ & 0,0610 & $-0,1144$ & 0,0312 \\
\hline Freezer & 0,3868 & $-0,0942$ & 0,2496 & $-0,3099$ & 0,2716 & 0,0899 & 0,7437 & 0,0564 & $-0,2121$ \\
\hline Lavadora & 0,3801 & $-0,1868$ & 0,3719 & $-0,1984$ & 0,2527 & 0,0045 & $-0,5756$ & 0,4943 & $-0,0575$ \\
\hline Carro & 0,4474 & $-0,2673$ & 0,0560 & $-0,1170$ & $-0,0696$ & $-0,0346$ & $-0,0769$ & $-0,5108$ & 0,6623 \\
\hline Banheiro & 0,3118 & $-0,1675$ & $-0,0012$ & 0,3056 & $-0,7138$ & 0,3760 & 0,1327 & 0,3359 & $-0,0051$ \\
\hline Empregada & 0,1553 & $-0,4808$ & $-0,3549$ & 0,6296 & 0,4597 & $-0,0320$ & 0,0506 & 0,0337 & $-0,0792$ \\
\hline \multicolumn{10}{|c|}{ Tratamento Nível 2: Educação do Pai } \\
\hline TV & 0,4570 & 0,0907 & 0,1879 & $-0,0504$ & $-0,1791$ & 0,0408 & $-0,2220$ & $-0,4542$ & $-0,6751$ \\
\hline Rádio & 0,3181 & 0,2895 & 0,4397 & $-0,1037$ & $-0,1331$ & 0,6532 & 0,0928 & 0,3457 & 0,1961 \\
\hline DVD & 0,2316 & 0,5933 & 0,3002 & $-0,0087$ & 0,3774 & $-0,5683$ & $-0,0655$ & 0,0395 & 0,1812 \\
\hline Geladeira & 0,1121 & 0,4476 & $-0,4783$ & 0,7057 & $-0,0536$ & 0,2068 & 0,0645 & $-0,0995$ & 0,0227 \\
\hline Freezer & 0,3782 & $-0,0328$ & $-0,3336$ & $-0,2926$ & 0,2402 & $-0,0303$ & 0,7524 & 0,0626 & $-0,1744$ \\
\hline Lavadora & 0,3731 & $-0,1075$ & $-0,4479$ & $-0,1653$ & 0,2251 & 0,0352 & $-0,5800$ & 0,4786 & $-0,0631$ \\
\hline Carro & 0,4536 & $-0,2418$ & $-0,0981$ & $-0,0822$ & $-0,0725$ & 0,0176 & $-0,0944$ & $-0,5232$ & 0,6567 \\
\hline Banheiro & 0,3254 & $-0,2341$ & 0,1128 & 0,2984 & $-0,6066$ & $-0,4415$ & 0,1404 & 0,3931 & 0,0215 \\
\hline Empregada & 0,1727 & $-0,4793$ & 0,3438 & 0,5290 & 0,5687 & 0,0926 & 0,0509 & 0,0391 & $-0,0795$ \\
\hline \multicolumn{10}{|c|}{ Tratamento Nível 3: Educação do Pai } \\
\hline TV & 0,4562 & 0,0447 & 0,1854 & $-0,0291$ & $-0,2164$ & $-0,0724$ & $-0,1555$ & $-0,5071$ & $-0,6490$ \\
\hline Rádio & 0,3095 & 0,2391 & 0,4745 & $-0,0862$ & $-0,3605$ & 0,5944 & 0,0419 & 0,3176 & 0,1692 \\
\hline DVD & 0,2168 & 0,5438 & 0,4130 & $-0,0285$ & 0,5436 & $-0,3991$ & $-0,0730$ & 0,0465 & 0,1535 \\
\hline Geladeira & 0,0937 & 0,4748 & $-0,3547$ & 0,7774 & $-0,1071$ & 0,1172 & 0,0705 & $-0,0703$ & 0,0230 \\
\hline Freezer & 0,3606 & 0,1141 & $-0,3657$ & $-0,3174$ & 0,1798 & 0,0574 & 0,7431 & 0,1038 & $-0,1544$ \\
\hline Lavadora & 0,3550 & 0,0561 & $-0,4905$ & $-0,2025$ & 0,1602 & 0,1186 & $-0,6290$ & 0,3814 & $-0,0915$ \\
\hline Carro & 0,4586 & $-0,1961$ & $-0,1379$ & $-0,0626$ & $-0,0763$ & $-0,0398$ & $-0,0534$ & $-0,4856$ & 0,6944 \\
\hline Banheiro & 0,3508 & $-0,3211$ & 0,1041 & 0,2763 & $-0,3310$ & $-0,5693$ & 0,1049 & 0,4919 & 0,0063 \\
\hline Empregada & 0,2253 & $-0,5118$ & 0,1998 & 0,4057 & 0,5855 & 0,3542 & 0,0452 & 0,0306 & $-0,1075$ \\
\hline
\end{tabular}


